\title{
Early events in copper-ion catalyzed oxidation of
}

\section{$\alpha$-synuclein}

Manish K. Tiwari ${ }^{\mathrm{a}}$; Fabian Leinisch ${ }^{\mathrm{b}}$, Cagla Sahinc, Ian Max Møller ${ }^{\mathrm{d}}$, Daniel E. Otzen; Michael J. Davies ${ }^{\mathrm{b}}$ and Morten J. Bjerrum ${ }^{\mathrm{a} *}$

${ }^{a}$ Department of Chemistry, University of Copenhagen, Copenhagen, Denmark

${ }^{\mathrm{b}}$ Department of Biomedical Sciences, University of Copenhagen, Copenhagen, Denmark

${ }^{\mathrm{c}}$ Department of Molecular Biology and Genetics, Aarhus University, Aarhus C, Denmark

${ }^{\mathrm{d}}$ Department of Molecular Biology and Genetics, Aarhus University, Slagelse, Denmark

Running title: Copper-ion catalyzed oxidation of $\alpha$-synuclein

Abbreviations used: $\alpha-\mathrm{SN}, \alpha$-synuclein; PD, Parkinson's disease; Met, methionine; Tyr, tyrosine; His, histidine, AscH-' ascorbate; 2Na-EDTA, Ethylenediaminetetraacetic acid disodium salt; MOPS, 3-(N-morpholino) propane-sulfonic acid.

*Corresponding author at: Department of Chemistry, University of Copenhagen,

Universitetsparken 5, DK-2100 Copenhagen, Denmark

Email address: mobj@chem.ku.dk (M. J. Bjerrum) 
Running title: Copper-ion catalyzed oxidation of $\alpha$-synuclein

\section{HIGHLIGHTS}

- Met and Tyr oxidation are early and rapid events in $\mathrm{Cu}^{2+} / \mathrm{H}_{2} \mathrm{O}_{2}-$ mediated damage to $\alpha$-synuclein.

- Met sulfoxide and dityrosine detected within 5 min of $\mathrm{Cu}^{2+} / \mathrm{H}_{2} \mathrm{O}_{2}$ exposure to $\alpha$-synuclein.

- Carbonyl formation is a minor process in early $\mathrm{Cu}^{2+} / \mathrm{H}_{2} \mathrm{O}_{2}$ - mediated damage to $\alpha$-synuclein.

- Ascorbate limits Met and Tyr oxidation in $\mathrm{Cu}^{2+} / \mathrm{H}_{2} \mathrm{O}_{2} / \mathrm{AscH}^{-}-$mediated damage to $\alpha$-synuclein.

\section{GRAPHICAL ABSTRACT}


Running title: Copper-ion catalyzed oxidation of $\alpha$-synuclein

\section{ABSTRACT}

Previous studies on metal-ion catalyzed oxidation of $\alpha$-synuclein oxidation have mostly used conditions that result in extensive modification precluding an understanding of the early events in this process. In this study, we have examined time-dependent oxidative events related to $\alpha-$ synuclein modification using six different molar ratios of $\mathrm{Cu}^{2+} / \mathrm{H}_{2} \mathrm{O}_{2} /$ protein and $\mathrm{Cu}^{2+} / \mathrm{H}_{2} \mathrm{O}_{2}$ /ascorbate/protein resulting in mild to moderate extents of oxidation. For a $\mathrm{Cu}^{2+} / \mathrm{H}_{2} \mathrm{O}_{2}$ /protein molar ratio of 2.3:7.8:1 only low levels of carbonyls were detected (0.078 carbonyls per protein), whereas a molar ratio of 4.7:15.6:1 gave 0.22 carbonyls per $\alpha$-synuclein within 15 min. With the latter conditions, rapid conversion of 3 out of 4 methionines (Met) to methionine sulfoxide, and 2 out of 4 tyrosines (Tyr) were converted to products including interand intra-molecular dityrosine cross-links and protein oligomers, as determined by SDS-PAGE and Western blot analysis. Limited histidine (His) modification was observed. The rapid formation of dityrosine cross-links was confirmed by fluorescence and mass-spectrometry. These data indicate that Met and Tyr oxidation are early events in $\mathrm{Cu}^{2+} / \mathrm{H}_{2} \mathrm{O}_{2}$-mediated damage, with carbonyl formation being a minor process. With the $\mathrm{Cu}^{2+} / \mathrm{H}_{2} \mathrm{O}_{2} /$ ascorbate system, rapid protein carbonyl formation was detected with the first $5 \mathrm{~min}$, but after this time point, little additional carbonyl formation was detected. With this system, lower levels of Met and Tyr oxidation were detected (2 Met and 1 Tyr modified with a $\mathrm{Cu}^{2+} / \mathrm{H}_{2} \mathrm{O}_{2}$ /ascorbate/protein ratio of 2.3:7.8:7.8:1), but greater His oxidation. Only low levels of intra- dityrosine cross-links and no inter- dityrosine oligomers were detected under these conditions, suggesting that ascorbate limits $\mathrm{Cu}^{2+} / \mathrm{H}_{2} \mathrm{O}_{2}$ induced $\alpha$-synuclein modification.

Keywords: $\alpha$-Synuclein, Metal-catalyzed oxidation, Oxidative stress, Parkinson's disease,

Dityrosine, Methionine sulfoxide, Protein carbonyls, Cross-links. 
Running title: Copper-ion catalyzed oxidation of $\alpha$-synuclein

\section{1. Introduction}

2 One-electron reduction of $\mathrm{O}_{2}$ by electron-transfer chains of mitochondria gives rise to superoxide

3 anion $\left(\mathrm{O}_{2}{ }^{--}\right)$and subsequently hydrogen peroxide $\left(\mathrm{H}_{2} \mathrm{O}_{2}\right)$ [1, 2]. Further reactions of these species

4 can generate the hydroxyl radical $\left({ }^{\circ} \mathrm{OH}\right)$, as well as non-radical species such as singlet oxygen

$5 \quad\left({ }^{1} \mathrm{O}_{2}\right)$. The formation and subsequent reactions of these species are therefore a significant feature

6 of aerobic life [3, 4]. Excessive production of these species, and/or impaired antioxidant defense

7 mechanisms, can give rise to increased oxidative stress in cellular systems [5] and has been

8 implicated in various pathological conditions including Parkinson's disease (PD) [6],

9 Alzheimer's disease (AD) [7, 8], Amyotrophic Lateral Sclerosis (ALS) [9], Huntington disease

10 (HD) [10] and Prion diseases [11] leading to neurodegeneration and cell death [1].

$\mathrm{PD}$, the second most prevalent neurodegenerative disease after $\mathrm{AD}$ [12], is characterized

12 by gradual impairment of physical abilities due to severe loss of dopaminergic neurons in the

13 substantia nigra region of the brain of PD patients [13]. PD mostly occurs sporadically, but

14 genetically inherited PD accounts for $\sim 15 \%$ of all cases [14]. A central hallmark of PD is the

15 intraneuronal aggregation of the protein $\alpha$-synuclein $(\alpha$-SN) into amyloid-rich Lewy bodies [15,

16 16]. $\alpha-\mathrm{SN}$ is a 140 amino acid presynaptic protein [17] with a relatively undefined regulatory

17 function, though it is believed to be involved in synaptic regulation [18]. Native $\alpha-\mathrm{SN}$ consists of

18 three distinct domains: a lipid-binding N-terminal region (residues 1 - 60), a hydrophobic self-

19 aggregating non-amyloid $\beta$ component (residues 61 - 95), and an acidic C-terminal region

20 (residues 96 - 140) that prevents rapid filament assembly [19]. A clear correlation between the

21 formation of intracellular oligomeric species of $\alpha-\mathrm{SN}$ within the substantia nigra and PD has

22 been reported, and it has been suggested that transient partially-folded $\alpha-\mathrm{SN}$ species are key to

23 fibrillization [20]. Although it is unclear how $\alpha-\mathrm{SN}$ triggers neuronal death [21] and aggregation 
Running title: Copper-ion catalyzed oxidation of $\alpha$-synuclein

24 of $\alpha-\mathrm{SN}$ has been attributed to complex processes, oxidatively generated damage appears to be a 25 major risk factor [22, 23]. Oxidized forms of methionine (Met) [24] and tyrosine (Tyr) [25, 26] have been shown to be abundant in Lewy body deposits [26], consistent with a role for oxidative stress in PD [1, 2]. Elevated levels of Fe ions $[27,28]$ in the substantia nigra and altered Cu ion concentrations [29] have been reported in PD brains, and evidence has been presented that dysregulated metal ion (iron, copper, and zinc) homeostasis is directly linked to the pathological processes of protein aggregation and oxidatively generated damage in PD and other neurodegenerative conditions [2, 30]. In vitro studies have suggested that fibrillation of $\alpha-\mathrm{SN}$ is promoted by metal ions [31], with $\mathrm{Cu}^{2+}$ the most effective [32]. Moreover, $\mathrm{Cu}^{2+}$ accelerates aggregation of $\alpha-\mathrm{SN}$ in vitro, via oxidation of $\mathrm{C}$-terminal residues [32]. However, the early molecular events leading to the transient conversion of unstructured monomeric $\alpha-\mathrm{SN}$ into oligomers and fibrils have yet to be defined.

Several structural and dynamic studies [33, 34] have focused on elucidating $\mathrm{Cu}^{2+}$ 37 coordination and structural determinants of $\mathrm{Cu}^{2+}$ binding to $\alpha-\mathrm{SN}$ [32, 35-37], and the role of metal ion-catalyzed oxidation (MCO) on $\alpha-S N$ aggregation/oligomerization [24, 26, 31, 38-41].

39 These studies have used $\mathrm{Cu}^{2+}$ concentrations in the range $500 \mu \mathrm{M}-5000 \mu \mathrm{M}$, with $300-1250$ $\mu \mathrm{M} \mathrm{H} \mathrm{H}_{2} \mathrm{O}_{2}$ and 100 pmol $-37 \mu \mathrm{M} \alpha-\mathrm{SN}$, resulting in high metal-ion : protein ratios $(13-130$

41 fold), and high $\mathrm{H}_{2} \mathrm{O}_{2}$ : protein ratios (8-34 fold) [26, 31, 38-40], with this resulting in extensive 42 oxidation. Furthermore, many studies have used long incubation periods (16 - $24 \mathrm{~h})$ [26, 38], and 43 buffers that contain phosphate [38, 41] or Tris [31, 39], which can act as metal ion chelators [42]. 44 These studies are summarized in Table S1. Although these studies have confirmed that metal 45 ions, such as $\mathrm{Cu}^{2+}$ can catalyze oxidation of PD, the relationship between the early events of $\alpha-$ 46 SN oxidation, and the chemical and structural changes that may lead to aggregation are still 47 unclear. 
Running title: Copper-ion catalyzed oxidation of $\alpha$-synuclein

The aim of the present study was, therefore, to systematically investigate: i) the effects of

49 low to moderate levels of $\mathrm{Cu}^{2+}, \mathrm{H}_{2} \mathrm{O}_{2}$, and $\mathrm{AscH}^{-}$on $\alpha-\mathrm{SN}$ at physiological $\mathrm{pH}$ values and short 50 reaction times; and ii) to evaluate the structural and chemical changes that occur on the $\alpha-\mathrm{SN}$.

51 The resulting data may help elucidate the early alternations of $\alpha-S N$ that are involved in the 52 initiation of PD.

\section{2. Materials and methods}

55

\subsection{Materials}

Expression and purification of full-length recombinant human $\alpha-S N$ (residues 1-140) were achieved as described previously [43]. Stabilizer-free $30 \%$ hydrogen peroxide $\left(\mathrm{H}_{2} \mathrm{O}_{2}\right)$ and copper (II) chloride dihydrate $\left(\mathrm{CuCl}_{2} \times 2 \mathrm{H}_{2} \mathrm{O}\right)$ was supplied by Merck Chemicals $\mathrm{GmbH}$ (Darmstadt, Germany). Ethylenediaminetetraacetic acid disodium salt (2Na-EDTA) and 3-(Nmorpholino) propane-sulfonic acid (MOPS) were obtained from BDH Ltd. (Poole, England). LAscorbic acid was supplied by Sigma-Aldrich (St. Louis, MO, USA). All chemicals and reagents were obtained with highest purity grade (>99.5\%).

\subsection{Preparation of Buffer, Chemicals, and $\alpha$-Synuclein Solutions}

67

using Milli-Q water. The concentration of the $\mathrm{H}_{2} \mathrm{O}_{2}$ stock solution was quantified by UV-Vis absorbance (Milli-Qwater as blank) at $265 \mathrm{~nm}$ using $\varepsilon 10 \mathrm{M}^{-1} \mathrm{~cm}^{-1}$ [44]. Milli-Q water, buffer, $\alpha-\mathrm{SN}$ and chemical solutions were filtered using a $0.2 \mu \mathrm{m}$ filter before use. Purified wild-type $\alpha-$ SN was dissolved in freshly-prepared $20 \mathrm{mM}$ MOPS-NaOH buffer ( $\mathrm{pH}$ 7.4) and the 
Running title: Copper-ion catalyzed oxidation of $\alpha$-synuclein

71 concentration determined from its UV absorbance (Agilent UV-visible ChemStation) at $280 \mathrm{~nm}$

72 using an extinction coefficient of $5960 \mathrm{M}^{-1} \mathrm{~cm}^{-1}[45]$.

\section{3. $\mathrm{Cu}^{2+}-$ mediated oxidation of $\alpha-\mathrm{SN}$}

A constant concentration of $\alpha-\mathrm{SN}(57.6 \mu \mathrm{M})$ was employed with the final concentrations

77 of the oxidant systems being as follows: $\mathrm{Cu}^{2+}(135-270 \mu \mathrm{M}), \mathrm{H}_{2} \mathrm{O}_{2}(450-900 \mu \mathrm{M})$ and $\mathrm{AscH}^{-}$

78 (450 - $900 \mu \mathrm{M})$, with six combinations of these examined (hereafter defined as condition 1- 6;

79 see Table 1$)$. The components were mixed at room temperature $\left(22^{\circ} \mathrm{C}\right)$ and a sample aliquot was

80 removed and quenched immediately after mixing with EDTA ( $<8$ s) and placed on ice. This

81 sample is defined as the 0.1 min incubation time point. The remaining material was transferred to

82 a $37{ }^{\circ} \mathrm{C}$ heating block, and further aliquots withdrawn at 5, 15, 30, 60, 180 and 360 min of

83 incubation. Immediately after sampling the reactions were quenched with 2 mM EDTA, a

84 concentration shown in pilot studies to prevent further oxidation. Control samples were also

85 prepared at the 0.1 and 360 min time points, each with one component of the reaction system.

86 Samples were aliquoted into separate tubes and flash frozen in liquid $\mathrm{N}_{2}$ and stored at $-80{ }^{\circ} \mathrm{C}$ for

87 further analysis.

\section{2.4. Determination of $\alpha-S N$ integrity by capillary electrophoresis}

92 Packard 3DCE (Agilent) equipped with UV-Vis diode array detector operating between 200 $93600 \mathrm{~nm}$. Separation was performed using a $75 \mathrm{~cm}$ x $0.005 \mathrm{~cm}$ fused silica capillary, with the $\mathrm{pH}$, 
Running title: Copper-ion catalyzed oxidation of $\alpha$-synuclein

94 ionic strength of the buffer and the voltage adapted to avoid any modification in the $\alpha-\mathrm{SN}$ charge

95 distribution as well as Joule effect. The temperature of capillary cassette was $25{ }^{\circ} \mathrm{C}$, the vial

96 holder temperature $15{ }^{\circ} \mathrm{C}$, the voltage $25 \mathrm{kV}$ with a typical current of $55 \mu \mathrm{A}$. The separation

97 buffer consisted of $50 \mathrm{mM} \mathrm{Na}$ phosphoric acid at $\mathrm{pH}$ 2.1. The capillary was rinsed with $1 \mathrm{M}$

$98 \mathrm{NaOH}$ for $10 \mathrm{~min}$ followed by $10 \mathrm{~min}$ with the Milli-Q water at 930 mbar. Prior to each run, the

99 capillary was rinsed with $0.1 \mathrm{M} \mathrm{NaOH}$ followed by the separation buffer for 3 min each. All 100 samples were injected at 50 mbar for $10 \mathrm{~s}$, with the capillary then plugged by injecting separation

101 buffer under the same conditions. On-column detection was at $220 \mathrm{~nm}$. Instrument control and 102 data acquisition were performed using ChemStation software (Agilent Technologies).

103

\subsection{Detection and quantification of protein carbonyls}

105 of each sample was mixed with the supplied fluorophore reagent and incubated for $\sim 16 \mathrm{~h}$ in darkness at $22{ }^{\circ} \mathrm{C}$. The samples were then precipitated with $400 \mu \mathrm{L}$ of cold trichloroacetic acid

111 (TCA) and unbound fluorophore removed by three washes with $1 \mathrm{~mL}$ cold acetone, each 112 followed by centrifugation at $10000 \mathrm{~g}$ for $15 \mathrm{~min}$ at $4{ }^{\circ} \mathrm{C}$. After evaporating residual acetone, the 113 pellets were solubilized using $50 \mu \mathrm{L}$ of the guanidinium chloride (GuHCl) provided with the kit 114 and incubated at $22{ }^{\circ} \mathrm{C}$. The dissolved pellets were diluted 6-fold by adding $250 \mu \mathrm{L}$ of assay 115 diluent and then centrifuged for $15 \mathrm{~min}$ at $4{ }^{\circ} \mathrm{C}$ at 10000 g. Samples and standards (100 $\left.\mu \mathrm{L}\right)$, in 116 duplicate, were placed into clear bottomed 96-well black fluorescence microtiter plate (Thermo 117 Scientific Nunc, Thermo Fisher) and fluorescence spectra recorded ( $\lambda_{\text {ex }} 485 \mathrm{~nm}, \lambda_{\text {em }} 530 \mathrm{~nm}$ ) 
Running title: Copper-ion catalyzed oxidation of $\alpha$-synuclein

118 using a Molecular Devices SpectraMax M2 instrument (Sunnyvale, CA, USA). The supplied

119 fluorophore standard was used to generate a standard curve in each assay run and the equation

120 obtained from the standard curve was used to calculate the carbonyl concentration in each

121 sample. With the exception of the incubations, all steps were undertaken at $4{ }^{\circ} \mathrm{C}$. Aliquots were

122 also taken prior to carbonyl quantification, for assessment of protein concentration using the

123 BCA assay [47]. Data are presented as the number of carbonyls per $\alpha-S N$ molecule.

124

125

\subsection{Examination of $\alpha-S N$ structure by circular dichroism}

J-815 spectropolarimeter equipped with a Peltier-element-controlled thermostat, using a spectral

128 bandwidth of $2 \mathrm{~nm}$, a digital integration time of $4 \mathrm{~s}$, a scanning speed of $20 \mathrm{~nm} \mathrm{~min}{ }^{-1}$, and a 129 0.005-cm path length cell. Blank spectra of the sample buffer (20 mM MOPS-NaOH buffer, pH 130 7.4) were subtracted from the mean spectrum of three individual scans, using the Jasco Spectra 131 Analysis software, and a Savitzky-Golay algorithm (of convolution width 11) applied.

\subsection{Amino acid analysis of $\alpha-S N$ samples}

Amino acid hydrolysis was carried out as described previously [48]. Hydrolyzed samples 135 were analyzed by UPLC using a Shimadzu Nexera system with an SIL-30AC autosampler (set at $1364{ }^{\circ} \mathrm{C}$ ) and a RF-20A fluorescence detector set with $\lambda_{\text {ex }} 340 \mathrm{~nm}, \lambda_{\text {em }} 440 \mathrm{~nm}$. Data analysis was 137 carried out using Shimadzu Lab Solutions Browser. Retention times and concentrations were 138 assigned by comparison to commercial amino acid standards, and data were normalized to the 139 alanine (Ala) content to compensate for any losses during processing [48]. 
Running title: Copper-ion catalyzed oxidation of $\alpha$-synuclein

140

141

142

143

144

145

146

147

148

149

150

151

152

153

154

155

156

157

158

159

160

161

\subsection{SDS-PAGE analysis of $\alpha-S N$ samples}

Samples were analyzed by SDS-PAGE to examine changes in protein integrity under reducing conditions. Samples and molecular mass markers (Invitrogen pre-stained marker 161036) were electrophoresed on 4-12\% NuPAGE Bis-Tris mini acrylamide gels (Invitrogen, Carlsbad, CA, USA) at $200 \mathrm{~V}$ for 40 min, before being stained using Coomassie Brilliant Blue.

\subsection{Detection of dityrosine cross-links}

$\alpha-$ SN samples (22 $\mu \mathrm{M}$ protein/well) were subjected to SDS-PAGE as described above and then electroblotted to nitrocellulose membranes (iBlot2, Thermofisher, $25 \mathrm{~V}$, $6 \mathrm{~min}$ ). The membranes were then washed with Tris-buffered saline (TBS) and blocked with Tris-buffered saline with $0.1 \%$ Tween mixed with bovine serum albumin (TBST-BSA) for $1 \mathrm{~h}$ at $22{ }^{\circ} \mathrm{C}$. The membranes were then probed with a primary mouse anti-dityrosine monoclonal antibody (Japan Institute for the Control of Aging; JaICA, 1:500 diluted in 1\% BSA/TBST) overnight at $4{ }^{\circ} \mathrm{C}$. Subsequently, the blots were washed four times with TBST for $15 \mathrm{~min}$, then incubated with an anti-mouse-HRP conjugate (1:2500 in 1\% BSA/TBST) for $1 \mathrm{~h}$ at $22{ }^{\circ} \mathrm{C}$, and then washed four times with TBST, followed by four times with TBS at $22{ }^{\circ} \mathrm{C}$. Bands were detected by chemiluminescence using ECL plus solution (Thermo Fisher) monitored using a SyngeneG: Box, with an automatic shutter speed.

Intrinsic fluorescence from Tyr and dityrosine was recorded at $305 \mathrm{~nm}$ and $405 \mathrm{~nm}$ respectively after excitation at $280 \mathrm{~nm}$ [26], using a Molecular Devices SpectraMax M2 instrument (Sunnyvale, CA, USA). 
Running title: Copper-ion catalyzed oxidation of $\alpha$-synuclein

162

\subsection{Electrospray ionization mass spectrometry (ESI-MS) analysis of $\alpha-S N$ samples}

ESI-MS analysis of samples was performed in the positive ion mode with a SolariX XR Bruker mass spectrometer coupled to a Dionex Ultimate 3000 high-performance liquid chromatography system without a column. Samples $(10 \mu \mathrm{L})$ were diluted with $100 \mu \mathrm{L} \mathrm{MeOH}$ containing $0.1 \%$ formic acid, and $100 \mu \mathrm{L}$ deionized $\mathrm{H}_{2} \mathrm{O}$ containing $0.1 \%$ formic acid. Samples were injected using the HyStar_LC at a flow rate of $3 \mu \mathrm{L} \mathrm{min}{ }^{-1}$. MS was operated at drying gas temperature of $200{ }^{\circ} \mathrm{C}$ source temperature, and a capillary voltage of $4000 \mathrm{~V}$. In source collision energy was $60 \mathrm{~V}$ whereas collision gas flow rate was 30\%. The lower and upper excitation event limits were 150 and $4000 \mathrm{~m} / \mathrm{z}$ respectively. Listed $\mathrm{m} / \mathrm{z}$ values in the tables are given for the monoisotopic mass. Data acquisitions and analysis were carried out using Compass ftms control and Compass data analysis software, respectively.

\subsection{Statistical analysis}

Data are presented as the mean and standard deviations of three replicates from three independent experiments unless otherwise stated. Statistical analysis was undertaken using the packages available in Excel with $\mathrm{p}<0.05$ taken as significant. 
Running title: Copper-ion catalyzed oxidation of $\alpha$-synuclein

182

183

\section{Results}

\section{1. $C u^{2+}$-catalyzed modification of $\alpha-S N$ determined by capillary electrophoresis (CE)}

$\alpha-\mathrm{SN}$ was subjected to six different sets of modification conditions at $37^{\circ} \mathrm{C}$, as indicated in the Materials and methods and Table 1 , with varying molar ratios of $\mathrm{Cu}^{2+}$ and $\mathrm{H}_{2} \mathrm{O}_{2}$ relative to $\alpha-\mathrm{SN}$, and for varying reaction times, before analysis by CE. Analysis of the samples from the earliest time point that could be examined (0.1 min; Fig. 1A) showed a single sharp and symmetric peak that eluted at 21 min, with a $10 \%$ loss of intensity compared to native $\alpha-$ SN (Fig. 1A). With longer incubation times (e.g. $5 \mathrm{~min}$ ) a significant loss of peak intensity ( 75\%) was observed, together with a new peak that eluted at 18 - 19 min (Fig. 1A), implying rapid modification of $\alpha-S N$. At longer time points (e.g. 60 min, Fig. 1A; 360 min, Fig. 1A) almost complete loss of the native $\alpha-S N$ peak was observed. The broadening of the protein peaks with increasing reaction time is assigned to the presence of a heterogeneous mixture of modified $\alpha-\mathrm{SN}$ species. These changes were not detected in any control sample (Supplementary texts and Fig. S1). With higher concentrations of $\mathrm{Cu}^{2+}$ and $\mathrm{H}_{2} \mathrm{O}_{2}$, an increased extent and rate of $\alpha-\mathrm{SN}$ degradation was observed (Supplementary Fig. S2 A-C).

\subsection{Quantification of protein carbonyls on modified $\alpha-S N$}

The carbonyl levels detected for control samples without added $\mathrm{Cu}^{2+}$ (Fig. S3A, Table S3) ranged from 0.0013 to 0.045 moles carbonyl per mole protein. Incubation of $\alpha-\mathrm{SN}$ with $\mathrm{Cu}^{2+}$ alone gave higher levels (0.047 moles/mole). With the complete reaction systems containing a 1:2.3:7.8 molar ratio of $\alpha-\mathrm{SN}(57.6 \mu \mathrm{M}): \mathrm{Cu}^{2+}: \mathrm{H}_{2} \mathrm{O}_{2}$ a higher level of carbonylation was detected, with the maximum yield of carbonyls of 0.092 moles/mole reached within 15 to 30 min 
Running title: Copper-ion catalyzed oxidation of $\alpha$-synuclein

204 (Fig. 2A); this level was then maintained for several hours (Fig. S3B and Table S4). With a 205 higher concentration of $\mathrm{Cu}^{2+}$ (condition 2), a significant increase in total carbonyl content (to 2060.147 moles/mole; Fig. 2A and Table S4) was detected, though the time course of formation was 207 similar to condition 1 (Fig. S3B). Compared to condition 1, higher ratios of $\mathrm{H}_{2} \mathrm{O}_{2}$ (condition 3) 208 increased the yield of carbonyls at all time points (Fig. 2A, S3B and Table S4). With the highest 209 concentrations of both $\mathrm{Cu}^{2+}$ and $\mathrm{H}_{2} \mathrm{O}_{2}$, (condition 4; Fig. 2A and Table S4) the highest yield of 210 carbonyls was observed (0.221 moles/mole after $15 \mathrm{~min})$. The time-dependence of carbonyl

211 formation with this system was similar to conditions 1 to 3 (Fig. S3B). Spiking experiment where 212 additional $\mathrm{Cu}^{2+}(135 \mu \mathrm{M}), \mathrm{H}_{2} \mathrm{O}_{2}(450 \mu \mathrm{M})$, and $\mathrm{AscH}^{-}(450 \mu \mathrm{M})$ were individually added into the 213 reaction mixture after $30 \mathrm{~min}$ did not show any significant change in the overall extent of 214 carbonyl formation (Fig. S3D).

\subsection{Effect of $\mathrm{Cu}^{2+}$-catalyzed oxidation on $\alpha-S N$ amino acid composition}

$\mathrm{Cu}^{2+}$-mediated oxidative modification was examined further by amino acid analysis. The experimentally-determined amino acid composition of the 15 residues investigated for the native $\alpha-\mathrm{SN}$ was very similar to the values predicted by the gene sequence (Fig. S4 and Table S5). Analysis of the control samples indicated that, except for the system containing $\alpha-\mathrm{SN}$ and $\mathrm{H}_{2} \mathrm{O}_{2}$

221 alone, no significant decrease in any amino acid, or increase in Met sulfoxide, occurred (Fig. S5, 222 Table S6). With $\alpha-\mathrm{SN}$, and $\mathrm{H}_{2} \mathrm{O}_{2}$ alone, a small decrease in Met was detected. This is possibly 223 due to slow direct reaction of $\mathrm{H}_{2} \mathrm{O}_{2}$ with the thioether function of Met residues, as observed in 224 other systems [49].

For the complete reaction system, with the lowest molar ratios of $\mathrm{Cu}^{2+}$ and $\mathrm{H}_{2} \mathrm{O}_{2}$ 226 (condition 1), a rapid and significant decrease in Met content ( $\sim 50 \%$ loss) was detected at the first 
Running title: Copper-ion catalyzed oxidation of $\alpha$-synuclein

227 time point examined (0.1 min; Fig. 3A). At $5 \mathrm{~min}, 75 \%$ of the Met were modified, and a further 228 slow decline was observed between 5 and 360 min (Fig. 3A). With an increased molar ratio of $229 \mathrm{Cu}^{2+}$ (condition 2), the loss of Met was $\sim 40 \%$ at $0.1 \mathrm{~min}, \sim 80 \%$ at $5 \mathrm{~min}$ (Fig. S6A) and almost 230 complete loss was detected at 360 min. Higher concentrations of $\mathrm{H}_{2} \mathrm{O}_{2}$ (condition 3; Fig. S7A) resulted in a comparatively slower modification of Met compared to higher $\mathrm{Cu}^{2+}$ concentrations.

232 However, with higher levels of both $\mathrm{Cu}^{2+}$ and $\mathrm{H}_{2} \mathrm{O}_{2}$ (condition 4), there was an additive loss of 233 Met (Fig. S8A). Control samples incubated for up to 360 min with EDTA alone revealed no 234 significant loss of Met over 360 min (Fig. S5 and Table S6).

235 With mild oxidative conditions (condition 1) approximately 50\% loss of Tyr residues was 236 observed at the 5 min time point (Fig. 3B, Table S7), and this increased to nearly $70 \%$ by 15 min 237 (Fig. 3B, Table S7). However, at longer time points (e.g. $60 \mathrm{~min}$ ) the rate of Tyr loss decreased 238 (Fig. 3B, Table S7). With higher $\mathrm{Cu}^{2+}$ concentrations (condition 2) a greater loss of Tyr (77\%) 239 was detected by 5 min (Fig. S6B, Table S8), and a similar increase in Tyr loss ( 70\%) was seen 240 with increased $\mathrm{H}_{2} \mathrm{O}_{2}$ concentrations (condition 3) (Fig. S7B and Table S9). With higher 241 concentrations of both reagents (condition 4) 90\% of the Tyr was consumed within 5 min, and 242 almost complete loss was detected at longer time points (Fig. S8B and Table S10). Control 243 samples incubated for 0 and 360 min with EDTA revealed (Fig. S5 and table S6) no Tyr loss over 244 this time period.

With regard to His loss, mild oxidative conditions (condition 1), resulted in a significant 246 (62\%) loss after 360 min (Fig. 3B, Table S7), but with higher $\mathrm{Cu}^{2+}$ concentrations (condition 2), a 247 slow accumulative loss of His was detected up to 60 min (Fig. S6B and Table S8). With higher $248 \mathrm{H}_{2} \mathrm{O}_{2}$ concentrations, or higher levels of both reagents (conditions 3 and 4) (Fig. S7B and S8B, 249 Tables S9, S10), no consistent trend was detected with regard to His loss, indicating a complex 250 molecular interplay. 
Running title: Copper-ion catalyzed oxidation of $\alpha$-synuclein

\subsection{Circular dichroism (CD) analysis of oxidation-induced changes in $\alpha-S N$ secondary}

structure

Figure S9 shows CD spectra of control and oxidized samples under the various oxidative

$256195 \mathrm{~nm}$ typical of random coil conformations, in agreement with previous observations [50].

257 Mild oxidative conditions (condition 1) did not induce significant alternations (Fig. S9B), but an

258 increase in the intensity of the negative shoulder at $218 \mathrm{~nm}$, and a decrease in the intensity of 259 the negative band at $\sim 198 \mathrm{~nm}$, was observed for conditions 2 to 6 over time (Figs. S9C - S9G); 260 possibly indicating a transformation from random coil conformation to a more $\beta$-rich backbone 261 structure.

262

263

\subsection{SDS analysis of oxidatively modified $\alpha-S N$}

Analysis of control samples (Fig. 4A) indicated the presence of monomeric $\alpha-\mathrm{SN}$ as

265 single band at $\sim 14.5 \mathrm{kDa}$, as expected, together with low levels of a species assigned to an $\alpha-\mathrm{SN}$ 266 dimer at $\sim 30 \mathrm{kDa}$. For the oxidized samples, the initial time point (0.1 min) showed an identical 267 dimeric band to the controls, but with increasing reaction time under mild oxidative conditions 268 (condition 1) increasing concentrations of bands assigned to the dimer and trimer were observed 269 (Fig. 4B), together with a band with an apparent mass slightly smaller than the parent $\alpha-\mathrm{SN}$ were 270 detected. The latter band is assigned to either a truncation or an altered conformation of the $\alpha-$ 271 SN. At longer time points (15 - $360 \mathrm{~min})$ under the same conditions, more pronounced formation 272 of SDS- and heat-stable dimer, trimer, and tetramer were detected (Fig. 4B), together with a loss 
Running title: Copper-ion catalyzed oxidation of $\alpha$-synuclein

273 of the parent $\alpha-\mathrm{SN}$ band (Fig. 4B). Higher levels of $\mathrm{Cu}^{2+}$ (condition 2; Fig. S10A) accelerated the

274 formation of dimer, trimer, and tetramer and loss of parent protein band (Fig. S10A). Higher

$275 \mathrm{H}_{2} \mathrm{O}_{2}$ concentrations (condition 3) showed less prominent dimer, trimer, and tetramer bands over

276 time, and more diffuse (smeared) bands were observed after 360 min of incubation (Fig. S10B).

277 Higher levels of both $\mathrm{Cu}^{2+}$ and $\mathrm{H}_{2} \mathrm{O}_{2}$ (condition 4) gave less intense bands for all species (Fig.

278 S10C) consistent with an overall loss of total native protein.

279

280

\subsection{Detection of dityrosine cross-links}

To probe whether the dimer, trimer, and tetramer seen by SDS-PAGE and pre-fibrillar

oligomers (molecular weight higher than a tetramer of $\alpha-\mathrm{SN}$ ) arise via dityrosine cross-linking,

283 Western blotting was conducted using an anti-dityrosine antibody. No dityrosine was detected

284 for control samples except for $\alpha-\mathrm{SN}$ incubated with $\mathrm{Cu}^{2+}$ alone for 360 min at $37{ }^{\circ} \mathrm{C}$, which

285 showed weak staining (Fig. 5A). However, $\alpha-\mathrm{SN}$ samples subjected to the complete oxidation

286 system (condition 1) showed a time-dependent increase in dityrosine-positive bands (Fig. 5A,

287 lanes 5 - 10), with little dityrosine detected at the earliest time point (0.1 min), but significant

288 formation at later times, with staining of the monomer, dimer, trimer, tetramer, and pre-fibrillar

289 oligomer bands. With increasing incubation time, the dityrosine staining was detected primarily

290 at the molecular mass of the pre-fibrillar oligomeric species (Fig. 5A). These data were

291 corroborated by intrinsic fluorescence measurements, where a rapid loss of the intrinsic Tyr

292 fluorescence signal (305 - $310 \mathrm{~nm}$ ) with an accompanying increase in fluorescence emission

293 intensity at $405-410 \mathrm{~nm}$, was detected with increasing incubation time with the complete

294 oxidation system (Fig. S11A). Control samples showed no change in Tyr or dityrosine

295 fluorescence intensity. With higher $\mathrm{Cu}^{2+}$ concentrations, a similar trend to that seen with 
Running title: Copper-ion catalyzed oxidation of $\alpha$-synuclein

296 297 lanes 1 to 5).

298

299

300

301

302

303

304

305

306

307

308

309

310

311

312

313

314

315

316

317

318

condition 1 was detected, however, the extent of formation was faster and more defined (Fig. 5B,

\subsection{ESI-MS analysis of modified $\alpha-S N$}

ESI-MS analysis of control $\alpha-\mathrm{SN}$ revealed an extended population with charge state ions of $11+$ to $19+$ (Fig. S12). As the 14+ charge state gave rise to the most intense peaks, further analyses concentrated on this state (Fig. S12A). Within the extended 14+ series, the MS spectrum showed species with $[\alpha-\mathrm{SN}+\mathrm{H}]^{+},[\alpha-\mathrm{SN}+\mathrm{H}+18]^{+}$, and $[\alpha-\mathrm{SN}+\mathrm{H}+58]^{+}$corresponding to monoisotopic $\mathrm{m} / \mathrm{z}$ values of 1033.25, 1034.54, and 1037.39, respectively (Fig. 6, Fig. S12B, Table S13). The $+18 \mathrm{Da}(1 \mathrm{O}+2 \mathrm{H})$ and +58 Da products (acetylated $\alpha-\mathrm{SN}+1 \mathrm{O})$ were of much lower abundance than the protonated $\alpha-\mathrm{SN}$ ion $\left([\alpha-\mathrm{SN}+\mathrm{H}]^{+}\right)$(Fig. S12B, Table S13). The simulated MS spectra for the unoxidized- $\alpha-S N, \alpha-S N+18 \mathrm{Da}$, and $\alpha-\mathrm{SN}+58 \mathrm{Da} \alpha-\mathrm{SN}$ species (Figs. S12C - S12D), showed an identical monoisotopic $m / z$ distribution. This suggests only minimal $\alpha-S N$ modification during purification and handling.

ESI-MS analysis of $\alpha-S N$ exposed to condition 1 for varying time periods is shown in Fig. 6 and Table S14. The 0.1 min sample gave rise to a mixture of signals, the most prominent of which had mono isotopic m/z values of 1034.39 (+ $16 \mathrm{Da}), 1035.54$ (+ $32 \mathrm{Da})$, and 1036.68 (+ $48 \mathrm{Da}$ ) corresponding to three distinct oxidized and protonated $\alpha-\mathrm{SN}$ species. The 5 min sample (Fig. 6C, Table S14) showed complete loss of the $\mathrm{m} / \mathrm{z} 1033.25$ signal corresponding to unmodified $\alpha-$ SN, and new species with $m / z$ values of $1036.46(+45 \mathrm{Da}$; + $3 \mathrm{O}-3 \mathrm{H}), 1035.32$ (+ $30 \mathrm{Da} ;+2 \mathrm{O}-3 \mathrm{H}), 1037.60(+62 \mathrm{Da} ;+4 \mathrm{O}-3 \mathrm{H})$ and $1034.18(+13 \mathrm{Da} ;+1 \mathrm{O}-3 \mathrm{H})$. These values corresponding to the addition of three, two, four and one oxygen $(\mathrm{O})$ atoms and the loss of 3 hydrogen $(-3 \mathrm{H})$ atoms from each species (Table S14). The $15 \mathrm{~min}$ sample gave intense ions 
Running title: Copper-ion catalyzed oxidation of $\alpha$-synuclein

319

320

321

322

323

324

325

326

327

328

329

330

331

332

333

334

335

336

337

338

339

340

341

with $\mathrm{m} / \mathrm{z} 1037.46$ and 1036.39, corresponding to (+ $59 \mathrm{Da} ;+4 \mathrm{O}-3 \mathrm{H})$ and (+ $44 \mathrm{Da} ;+3 \mathrm{O}-3 \mathrm{H})$ suggesting incorporation of four and three oxygen atoms, respectively (Fig. 6D, Table S14). The abundance of acetylated $\alpha-S N$ present in the control samples decreased, and the abundance of this species with oxidative modifications increased, with increasing incubation time between 0.1 - 15 min (Table S14).

\subsection{Effect of ascorbate (AscH-) on $\mathrm{Cu}^{2+}-$ catalyzed damage to $\alpha-S N$}

The addition of $\mathrm{AscH}^{-}$to the mild oxidative reaction conditions (i.e. condition 1 with $\mathrm{AscH}^{-}$at the same molar ratio as $\mathrm{H}_{2} \mathrm{O}_{2}$; condition 5, Table 1) resulted in more rapid changes to the species detected with CE (Fig. 1B). Thus the 0.1 min time point sample showed a $50 \%$ loss of intensity compared to the unoxidized sample and the appearance of two new peaks at 18 (weak) and $21 \mathrm{~min}$. At longer time points the parent $\alpha-\mathrm{SN}$ peak continued to decrease in intensity, whilst the peak at 21 min increased, then remained at a plateau value for the remaining time period examined (Fig. 1B). With higher concentrations of $\mathrm{AscH}^{-}$(condition 6; Table 1, Fig. S2D), the overall migration pattern of oxidized $\alpha-\mathrm{SN}$ remained the same. Control samples showed no significant changes (Fig. S1).

The presence of $\mathrm{AscH}^{-}$(as above) also modulated the yield and time course of protein carbonyl formation, with a rapid initial increase, and then a plateau level of carbonyls detected over the remaining incubation time (Fig. 2B). This plateau level was not significantly different with the two different $\mathrm{AscH}^{-}$concentrations. The initial rate of increase in the presence of $\mathrm{AscH}^{-}$ was more rapid than seen in the absence of $\mathrm{AscH}^{-}$, but the plateau level was much lower $(\sim 0.07$ moles/mole; Fig. 2B, Table S4), than for all of the conditions $(1-4)$ in which $\mathrm{AscH}^{-}$was not present (Fig. 2A). 
Running title: Copper-ion catalyzed oxidation of $\alpha$-synuclein

Consistent with the above time course data, analysis of the consumption of parent amino

343 acids, and formation of Met sulfoxide, in the presence of $\mathrm{AscH}^{-}$showed significant differences to

344 the absence of $\mathrm{AscH}^{-}$. After 0.1 min incubation with mild oxidative conditions with $\mathrm{AscH}^{-}$

345 present (condition 5), 50\% of the Met residues had been converted to Met sulfoxide (Fig. 3C),

346 and these values remained constant at longer incubation times. With the higher concentration of

$347 \mathrm{AscH}^{-}$, and the highest concentrations of $\mathrm{Cu}^{2+}$ and $\mathrm{H}_{2} \mathrm{O}_{2}$ (condition 6), 3 Met residues were lost

348 by the 0.1 min time point, and this remained constant at longer time points (Fig. S13A). For Tyr

349 residues, a similar rapid, but lower overall loss was detected compared to the absence of AscH ${ }^{-}$.

350 Thus 33\% Tyr was lost at $0.1 \mathrm{~min}$, and by 360 min incubation only 38\% was consumed (Fig.

$3513 \mathrm{D}$ and Table S11), and these levels were not significantly greater with the higher molar ratios of

$352 \mathrm{Cu}^{2+}, \mathrm{H}_{2} \mathrm{O}_{2}$, and $\mathrm{AscH}^{-}$(Fig. S13B and Table S12). In contrast to the above, a more significant

353 decrease in the levels of His were detected in the presence of $\mathrm{AscH}^{-}$compared to its absence (Fig.

354 3D, Table S11 with $\sim 42 \%$ His oxidized after $0.1 \mathrm{~min}$, and a further slow loss detected at $15 \mathrm{~min}$

355 ( 65\%), after which the values remained unchanged (Fig. 3D, Table S11). A similar trend was

356 seen for the incubations with higher molar ratios (condition 6; Fig. S13B, Table S12).

Consistent with the above data, less dramatic changes were seen for the $\alpha-S N$ samples

358 examined by SDS-PAGE in the presence compared to absence of AscH $^{-}$(Fig. 4C, Fig. S10D).

359 Formation of the dimer, trimer, tetramer, and pre-fibrillar oligomer bands were not detected

360 above those detected for controls. The presence of $\mathrm{AscH}^{-}$also decreased the intensity of the band 361 detected at slightly lower mass than the parent $\alpha-S N$ (Fig. 4C vs. 4B), though an additional low362 intensity band was detected at $\sim 4.5 \mathrm{kDa}$ for both conditions 5 and 6 (Figs. 4C, and S10D), 363 which was not detected in the absence of $\mathrm{AscH}^{-}$. Consistent with the minor consumption of Tyr 364 detected by amino acid analysis, only low-intensity dityrosine bands resembling monomer were 
Running title: Copper-ion catalyzed oxidation of $\alpha$-synuclein

365

366

367

368

369

370

371

372

373

374

375

376

377

378

379

380

381

382

383

384

385

386

detected by Western blotting (Fig. 5B, lanes $6-10$ ). This observation is further supported by limited loss of the intrinsic fluorescence of Tyr at $305-310 \mathrm{~nm}$ (Fig. S11B), or insignificant increase in dityrosine at $405-410 \mathrm{~nm}$ (Fig. S11B inset).

Consistent with the rapid rate of Met and Tyr loss and protein carbonyl formation detected in the presence of AscH- ESI-MS analysis of the samples oxidized in the presence of $\mathrm{AscH}^{-}$showed extensive modification at the $0.1 \mathrm{~min}$ time point (Fig. 7, Table S15), with an intense signal with monoisotopic $\mathrm{m} / \mathrm{z}$ values of 1036.6 (+ $47 \mathrm{Da})$ detected. This species was the most prominent ion detected for the $0.1 \mathrm{~min}, 5 \mathrm{~min}$, and $15 \mathrm{~min}$ time points, and corresponds to the addition of three oxygen atoms to a protonated $\alpha-\mathrm{SN}$ and loss of a hydrogen atom. Oxidized $\alpha-\mathrm{SN}$ species with 1 to 6 added oxygen atoms on protonated $\alpha-\mathrm{SN}$ were also evident at the 0.1 min time point, with only low levels of ions from unmodified $\alpha-S N(m / z ~ 1033.25)$. This ion was not however detected at the 5 and 15 min time points (Fig. 7C, D, and Table S15) consistent with complete loss of parent $\alpha-\mathrm{SN}$ (cf. the CE data). Acetylated $\alpha-\mathrm{SN}$ was also detected with oxidative modifications.

\section{Discussion}

\subsection{The mechanism of metal-catalyzed protein oxidation}

Our understanding of the factors and particularly the role of oxidatively generated damage that contribute to early $\alpha-\mathrm{SN}$ aggregation/oligomerization is limited. Oxidatively generated damage to $\alpha$-SN by metal ion- and/or $\mathrm{H}_{2} \mathrm{O}_{2}$-mediated systems has not been completely elucidated, and the available data are somewhat contradictory due to the harsh oxidative conditions used in some studies (Table S1) [20, 24, 26, 31, 39-41]. The high $\mathrm{Cu}^{2+} / \mathrm{H}_{2} \mathrm{O}_{2}$ 
Running title: Copper-ion catalyzed oxidation of $\alpha$-synuclein

387 concentrations and molar ratios to $\alpha-S N$ employed, and the use of chelating buffers makes 388 extrapolation from these studies to in vivo studies difficult. Intracellular local concentrations of

$\underline{\alpha-\mathrm{SN}}$ are suggested to be $\sim 20-100 \mu \mathrm{M}$ in the brain where $\alpha-\mathrm{SN}$ is naturally abundant [51]. The

390 intracellular copper ion concentrations has been reported to reach up to $15 \mu \mathrm{M}$ in brain

391 synaptosomes and $\sim 300 \mu \mathrm{M}$ in synaptic vesicles where $\alpha-\mathrm{SN}$ is enriched [52]. Additionally,

392 evidence has been also put forward for a dynamic pool of loosely bound copper ions that could

393 interact with $\alpha-\mathrm{SN}$ [53]. The current study was designed to use concentration not too far from

394 these biological conditions.

395 Of the previously examined metal ion-catalyzed systems [54], the $\mathrm{Cu}^{2+} / \mathrm{H}_{2} \mathrm{O}_{2}$ system was

396 chosen, as elevated $\mathrm{Cu}^{2+}$ concentrations have been linked to elevated oxidative stress [35],

397 oligomerization of $\alpha-S N$ [32] and Lewy body formation [26]. The mechanism for the reaction in

398 the absence of $\mathrm{AscH}^{-}$has been suggested to be [55]:

399

(I) $\quad \mathrm{Cu}^{2+}+\mathrm{H}_{2} \mathrm{O}_{2} \rightarrow \mathrm{Cu}^{+}+\mathrm{O}_{2}^{-\bullet}+2 \mathrm{H}^{+}$

400

(II) $\mathrm{Cu}^{2+}+\mathrm{O}_{2}^{-\bullet} \rightarrow \mathrm{Cu}^{+}+\mathrm{O}_{2}$

401

(III) $\mathrm{Cu}^{+}+\mathrm{H}_{2} \mathrm{O}_{2} \rightarrow \mathrm{Cu}^{2+}+\mathrm{HO}^{-}+\mathrm{HO}^{\bullet}$

402 In the presence of $\mathrm{AscH}^{-}$, the reduction of $\mathrm{Cu}^{2+}$ by $\mathrm{AscH}^{-}$could facilitate production of $\mathrm{Cu}^{+}$as 403 described by the equation below [56].

404

(IV) $\mathrm{Cu}^{2+}+\mathrm{AscH}^{-} \rightarrow \mathrm{Cu}^{+}+\mathrm{Asc}^{-\bullet}+\mathrm{H}^{+}$

405 Although extensively studied, the oxidizing species produced by reaction of protein-copper

406 complexes with $\mathrm{H}_{2} \underline{\mathrm{O}}_{2}$ remains contentious. Several studies focused on DNA damage mediated by

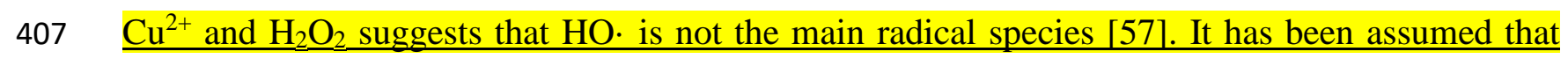


Running title: Copper-ion catalyzed oxidation of $\alpha$-synuclein

408

409

410

411

412 416 conditions employed [59].

the reduction of protein-bound $\mathrm{Cu}^{2+}$ to $\mathrm{Cu}^{+}$, can take place by either $\mathrm{H}_{2} \mathrm{O}_{2}$ (reaction I) or by superoxide radical anions. $\mathrm{Cu}^{+}$can then participate in a Fenton-like reaction with additional $\mathrm{H}_{2} \mathrm{O}_{2}$ (reaction III). This would generate $\mathrm{Cu}^{2+}-\mathrm{HO}$ or its ionized equivalent, $\mathrm{Cu}^{2+}-\mathrm{O}^{*}$, as proposed earlier [58]. Although not examined here in detail, we do not rule out the possibility that more than one active species is involved in random and site-specific damage to $\alpha$-SN.

The effect of multiple different molar ratios of $\mathrm{Cu}^{2+} / \mathrm{H}_{2} \mathrm{O}_{2} / \mathrm{AscH}^{-}$were evaluated over time up to $360 \mathrm{~min}$ (Table 1), with the experiments carried out using $20 \mathrm{mM}$ MOPS-NaOH, $\mathrm{pH}$ 7.4, as this buffer does not complex $\mathrm{Cu}^{2+}$ readily, is stable and is not readily oxidized under the

\subsection{Side-chain carbonylation is not one of the major early events in MCO of $\alpha-S N$}

CE provides a robust platform [60] to examine the effects of $\mathrm{Cu}^{2+}, \mathrm{H}_{2} \mathrm{O}_{2}$, and $\mathrm{AscH}^{-}$on $\alpha-$

SN. The peak from native $\alpha-S N$ was converted to multiple additional species over the time course examined with the rate and extent of this process depends on the presence and concentrations of $\mathrm{Cu}^{2+}, \mathrm{H}_{2} \mathrm{O}_{2}$ and $\mathrm{AscH}^{-}$(Figs. 1, and S2). Protein oxidation is known to generate various chemical as well as structural modifications, including altered charge and conformation. $\underline{\text { Such oxidatively induced modifications would result in different electrophoretic migration and }}$ can be monitored by CE as shown previously [61]. Figure 1A shows electrophoretic migration of $\underline{\text { control and oxidized } \alpha \text {-SN under condition } 1 \text {. Two small peaks with migration time } \sim 18-19 \text { min }}$ can be seen at the earliest time interval $(0.1 \mathrm{~min})$, with increasing intensity of same peaks up to 60 min. The rapid formation of Met sulfoxide and dityrosine as observed by amino acid and western blot analyses within the same time interval $(0.1-60 \mathrm{~min})$ suggests that these newly formed peaks with changed electrophoretic migration may represent isoforms with Met and Tyr oxidations. It is interesting to note that the near disappearance of native $\alpha$-SN peak correlates 
Running title: Copper-ion catalyzed oxidation of $\alpha$-synuclein

432

433

434

435

436

437

438

439

440

441

442

443

with the loss of native $\alpha$-SN band on SDS-PAGE (Fig. 4B). The loss of peak resolution after 60 min could be due to the heterogeneous mixture of oxidized $\alpha$-SN species as judged by western blot (Fig. 5B). On the other hand, the near absence of the peaks in figure 1B under condition 5 (condition 1 with $\mathrm{AscH}^{-}$) appears to reflect limited Met and Tyr oxidation. These data, and also those from the other complementary techniques employed, indicate that major changes to $\alpha-\mathrm{SN}$ occur over a period of seconds to minutes and that the rate of change is considerably slower after 15 min. The presence of $\mathrm{AscH}^{-}$(conditions 5 and 6) markedly changed the observed behavior, with this occurring more rapidly, but also to a lower overall extent, with a rapid "burst" of oxidation on the seconds time scale, followed by near plateau values over the remaining time period. Furthermore, the different pattern of peaks detected by CE, the changes in protein carbonyl levels, the differences in amino acid consumption, and the bands detected by SDSPAGE, are consistent with different processes occurring in the presence of $\mathrm{AscH}^{-}$.

Although protein-bound carbonyls are widely used as a biomarker, and a quantitative measure of oxidative stress [5, 62], previous studies on $\alpha-\mathrm{SN}[24,38,39]$ have not measured carbonyl formation. The data obtained here show, with a wide variety of different concentrations and molar ratios of $\mathrm{Cu}^{2+}, \mathrm{H}_{2} \mathrm{O}_{2}$, and $\mathrm{AscH}^{-}$that: i) limited carbonyl formation occurs within the first 5 min of reaction with $\mathrm{Cu}^{2+} / \mathrm{H}_{2} \mathrm{O}_{2}$ system; ii) that the $\mathrm{Cu}^{2+}$ concentration is a major driver of the extent of this process; iii) that $\alpha-S N$ can be oxidized in the absence of reducing agents; and iv) that carbonyl generation follows a similar time course under all of the conditions examined (Figs. 2 and S3). However, the overall levels of protein carbonyls detected all of the conditions examined is rather low and reaches a maximum level of only $\sim 20 \%$ of the $\alpha-\mathrm{SN}$ molecules carrying a single carbonyl function. The plateau values detected for the carbonyl levels could be due to depletion of $\mathrm{H}_{2} \mathrm{O}_{2}$ or $\mathrm{Cu}^{2+}$ in the solution. Thus, whenever $\mathrm{Cu}^{+}$is formed some fraction will disproportionate according to the equation: 
Running title: Copper-ion catalyzed oxidation of $\alpha$-synuclein

(V) $2 \mathrm{Cu}^{+}(a q) \leftrightarrows \mathrm{Cu}$ and $\mathrm{Cu}^{2+}(a q)$

This would be expected to slowly remove $\mathrm{Cu}^{2+}$ ions from solution as metallic copper 460 thereby slowing down the observed rate of oxidation. However, the spiking experiments where

461 more $\mathrm{Cu}^{2+}, \mathrm{H}_{2} \mathrm{O}_{2}$, and $\mathrm{AscH}^{-}$were individually added to the reactions after 30 min suggest that 462 this is not the complete reason for the plateau values and that other factors must play a significant 463 role.

464 The stimulation of protein carbonyl formation in the presence of $\mathrm{AscH}^{-}$compared to its 465 absence (i.e. condition 5 vs. condition 1), may arise from enhanced reuduction of $\mathrm{Cu}^{2+}$ to $\mathrm{Cu}^{+}$ 466 (reaction IV) by $\mathrm{AscH}^{-}$. The higher concentration of $\mathrm{Cu}^{+}$might increase the initial rate of 467 carbonyl formation (reaction III), allowing a rapid initial burst of carbonyl generation at early 468 stage of MCO. However, due to potential radical scavenging ability of AscH', the overall 469 carbonyl generation could be lowered by means of i) limiting the concentration of reactive 470 species that react with the $\alpha-$ SN (i.e. via direct scavenging of the initial oxidant species [63]; and 471 ii) by repair of initial radical species formed on the $\alpha-S N$, a rapid process demonstrated for Tyr 472 phenoxyl radicals [64]. Despite the different time courses of carbonyl formation detected with the

$473 \mathrm{Cu}^{2+} / \mathrm{H}_{2} \mathrm{O}_{2}$ and the $\mathrm{Cu}^{2+} / \mathrm{H}_{2} \mathrm{O}_{2} / \mathrm{AscH}^{-}$systems, the carbonyl content in both systems rapidly 474 reached a plateau value after 30 - 60 minutes (Fig. 2). Similar observations on the extent of 475 overall carbonyl production have also been reported for bovine serum albumin (BSA) [65] and $\beta$ -

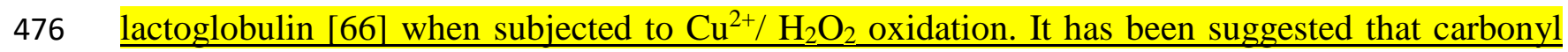
477 compounds are not the final product in the oxidation reaction and that they can be converted into 478 carboxylic acid either by auto-oxidation or by reaction with $\mathrm{H}_{2} \mathrm{O}_{2}$ [67]. Furthermore, lysine 479 residues can diminish the carbonyl content, by forming either Schiff base compounds or other 
Running title: Copper-ion catalyzed oxidation of $\alpha$-synuclein

cross-links [66]. If so, the relatively large number of lysine residues (15) present in $\alpha-S N$ may help account for the absence of further increases in carbonyl production. It is also noting that $\underline{\text { most rapidly and readily oxidized residues such methionines and tyrosines as in case of } \alpha-\mathrm{SN} \text { do }}$ not give high yields of carbonyls as products. Thus, although carbonyl levels are often used as an indicator of protein damage [68], our data indicate that significant damage to $\alpha$-SN may occur prior to a significant increase in the overall protein carbonyl level.

\subsection{Methionine oxidation occurs rapidly during $M C O$ of $\alpha-S N$}

The amino acid analysis of $\alpha-\mathrm{SN}$ carried out at different time points, and with different concentration of $\mathrm{Cu}^{2+}, \mathrm{H}_{2} \mathrm{O}_{2}$, and $\mathrm{AscH}^{-}$, confirms the rapid time course of changes in the protein and the occurrence of different reaction pathways. In the absence of added $\mathrm{Cu}^{2+}$, but with added $\mathrm{H}_{2} \mathrm{O}_{2}$, a slow loss of $\sim 1$ Met and formation of 1 mole of Met sulfoxide was detected, consistent with slow molecular oxidation at a single reactive Met residue (Fig. S5 and Table S6). All other control samples showed no measurable changes (Fig. S5 and Table S11). In the presence of the complete oxidation system (but without $\mathrm{AscH}^{-}$) rapid oxidation of two (on average) of the four Met residues in $\alpha-S N$ (Met-1, Met-5, Met-116, and Met-127) was detected by the 0.1 min time point. The other two Met residues were consumed more slowly, but oxidation of all the Met residues was essentially complete by 360 min (Figs. 3A, S6A, S7A, and S8A). This stepwise Met oxidation can be rationalized by the presence of a high-affinity $\mathrm{Cu}^{2+}$ binding site [32, 69] located in the $\mathrm{N}$-terminal region of $\alpha-\mathrm{SN}$ where Met- 1 and Met-5 are located. The formation of oxidants from $\mathrm{H}_{2} \mathrm{O}_{2}$ by $\mathrm{Cu}^{2+}$ bound at this site could result in rapid oxidation of these two $\mathrm{N}$-terminal Met residues followed by slower oxidation of the C-terminal Met-116 and Met-127 [70]. This observation is supported by ESI MS analyses (vide infra). However, it is interesting to note that whilst the mildest oxidation system (condition 1) showed immediate Met oxidation to Met 
Running title: Copper-ion catalyzed oxidation of $\alpha$-synuclein

504 sulfoxide (Fig. 3A), increasing the molar ratio of $\mathrm{Cu}^{2+}$ (condition 2; Fig. S6A), and an increased

505 molar ratio of $\mathrm{H}_{2} \mathrm{O}_{2}$ (condition 3; Fig. S7A), as well as increase molar ratio of both $\mathrm{Cu}^{2+} / \mathrm{H}_{2} \mathrm{O}_{2}$

506 (condition 4; Fig. S8A), appeared to slow down the rate of conversion of Met to Met sulfoxide,

507 possibly due to $\mathrm{Cu}^{2+}$ coordination with either $\alpha-\mathrm{SN}$ [71], or products of the initial reaction (e.g. a

508 sulfoxide- $\alpha-$ SN species). Inter- as well as intra-molecular coordination of multiple Met

509 sulfoxides with metal ions, have been suggested to alter fibrillation process of $\alpha-S N$ [31, 34].

510 Indeed, the more rigid and polar Met sulfoxide may alter protein structures [72] and result in

511 conformational transitions of the protein [73]. Thus, lower $\mathrm{Cu}^{2+}$ concentrations may favor a more

512 rapid oxidation of Met residues. Met sulfoxide has also been suggested to disrupt end-to-end

513 association of $\alpha-\mathrm{SN}$ and thus be inhibitory to fibrillation of $\alpha-\mathrm{SN}$ [74]. In line with this data,

$514 \mathrm{Cu}^{2+}$ has been reported to accelerate $\alpha-\mathrm{SN}$ aggregation with an inverse relationship to the $\mathrm{Cu}^{2+}$

515 concentration; however, the aggregation growth $\left(k_{a p p}\right)$ is not affected by overall $\mathrm{Cu}^{2+}$ ion

516 concentration [32].

$517 \mathrm{AscH}^{-}$is known to exhibit "crossover” effect as pro vs. antioxidant [75] depending on its 518 concentrations [76]. When $\mathrm{AscH}^{-}$was added to the mild oxidation system (condition 1) to give 519 condition 5, only two Met residues were oxidized over the 360 min (Fig. 3C). Interestingly, a 520 recent study has reported an intracellular repair mechanism where oxidized N-terminal Met 521 residues (Met-5 and Met-1) are repaired in a stepwise manner. However, the two C-terminal 522 species (Met-116 and Met-127) were oxidized to Met sulfoxide [70]. Thus the presence of $523 \mathrm{AscH}^{-}$may modulate the overall oxidation process by a continuous recycling of the $\mathrm{N}$-terminal 524 Met residues. However, an additive effect of $\mathrm{Cu}^{2+}$ and $\mathrm{H}_{2} \mathrm{O}_{2}$, with $\mathrm{AscH}^{-}$was seen in condition 6 525 (Fig. S13A), where three of four Met residues were fully oxidized by 360 min. Furthermore, the 526 concentration of Met sulfoxide does not appear constant with this decreasing after 5 min 
Running title: Copper-ion catalyzed oxidation of $\alpha$-synuclein

527 incubation (Fig. S13A), consistent with further reaction, possibly to the sulfone. This observation

528 is in agreement with the detection of Met sulfone under strongly oxidizing conditions [77].

4.4. Intra- and inter-molecular dityrosine formation is one of the major early events in MCO of $\alpha-S N$

It is established that the formation of dityrosine cross-links involves the transient generation of Tyr-derived phenoxyl radicals by one-electron oxidants [78], whereas Met

534 sulfoxide can be generated by both two- and one-electron oxidation reactions [79]. The four Tyr 535 residues at positions 39, 125, 133, and 136 have been implicated in the pathogenesis of PD via 536 dityrosine covalent cross-linking [26]. However, previous studies have not demonstrated early 537 conversion of these residues to dityrosine crosslinks. The amino acid analysis reported here 538 indicate that Tyr loss is an early event, with two Tyr residues consumed after 5 min incubation 539 (Fig. 3B), and $\sim 3$ three Tyr lost after $360 \mathrm{~min}$. The rapid loss of Tyr under conditions $1-4$, 540 suggests that the $\mathrm{Cu}^{2+}$ ion concentration is a major molecular driver of damage via Tyr-Tyr 541 coupling. However, inhibition of dityrosine formation in the presence of $\mathrm{AscH}^{-}$may occur via 542 removal of tyrosyl radicals.

\section{4.5. Site-specific oxidation of His-50 in the presence of $\mathrm{AscH}^{-}$}

545 Oxidation of the His residue in $\alpha-\mathrm{SN}$ with low $\mathrm{Cu}^{2+}$ concentrations (condition 1) appears to be 546 slower than for some of the Met and Tyr residues. This may be due to a binding interaction of 547 His-50 with $\mathrm{Cu}^{2+}$. The imidazole ring of His-50 is one of the $\mathrm{Cu}^{2+}$ binding sites at the $\mathrm{N}$ 548 terminus of $\alpha$-SN [80]. An explanation for the oxidation of His-50 in the presence of $\mathrm{AscH}^{-}$ 549 (condition 5) could be that, His-50-bound $\mathrm{Cu}^{2+}$ can be reduced to $\mathrm{Cu}^{+}$, which then interacts with 
Running title: Copper-ion catalyzed oxidation of $\alpha$-synuclein

550

551

552

553

554

555

556

557

558

559

560

561

562

563

564

565

566

567

568

569

570

571

572

573

exogenous $\mathrm{H}_{2} \mathrm{O}_{2}$ to oxidize the $\mathrm{H} 50$ side chain in a site-specific manner through copper coordination (Fig. 3D). Another possibility is that, in the presence of $\mathrm{AscH}^{-}$the Fenton-like reaction of $\mathrm{Cu}^{+}$with $\mathrm{H}_{2} \underline{\mathrm{O}}_{2}$ would specifically generate diffusible $\mathrm{HO}$; which then reacts at diffusion control with nearby residues such as His-50. The redox cycling of His-50-bound $\mathrm{Cu}^{2+}$, as well as a site-specific oxidation of His-50 in the presence of $\mathrm{AscH}^{-}$, shown in this study, supports the role of His-50 residues in copper coordination [81].

\subsection{Copper-ion catalyzed oxidation and structural changes in the absence and presence of} $\underline{\mathrm{AsCH}^{-}}$

The CD spectra obtained (Fig. S8) show random coil conformations for all the $\alpha-S N$ samples examined, with only modest, and poorly informative, differences between the conditions. More informative data was obtained by SDS-PAGE. Oxidation in the absence of $\mathrm{AscH}^{-}$resulted in dimer, trimer, tetramer, and pre-fibrillar oligomer formation, with the extent dependent on the oxidant concentrations (Fig. 4). These bands were shown to contain dityrosine by Western blotting (Fig. 5). Incubation for $5 \mathrm{~min}$, in the absence of $\mathrm{AscH}^{-}$, was sufficient to show a marked increase in (non-reducible and heat-stable) dityrosine formation, with the majority of the staining progressively appearing higher up the gel (i.e. at higher average molecular masses) with longer incubation times (Fig. S11A), consistent with rapid formation of dityrosine and pre-fibrillar oligomer assembly. The gradual decrease in overall dityrosine signal intensity (Fig. S11C) is possibly due to inaccessibility of the antibody to the antigen in the highly aggregated material.

In contrast, when $\mathrm{AscH}^{-}$was present, no formation of dimer, trimer, tetramer, and prefibrillar oligomer bands were detected by either SDS-PAGE gel (Fig. 4C), and Western blotting (Fig. 5B) or direct fluorescence measurements (Fig. S11B and S11C). This is consistent with 
Running title: Copper-ion catalyzed oxidation of $\alpha$-synuclein

574 rapid repair of Tyr phenoxyl radicals by $\mathrm{AscH}^{-}[82,83]$, and suggests a key role for $\mathrm{AscH}^{-}$in

575 limiting modification of $\alpha-S N$.

576 The ESI-MS analysis confirmed the rapid oxidation $\alpha-S N$ in both the absence and

577 presence of $\mathrm{AscH}^{-}$. The data obtained are consistent with limited and very rapid modification of

578 Met residues within the first fraction of a minute. Subsequent formation of dityrosine cross-links

579 in the absence of $\mathrm{AscH}^{-}$as indicated by the loss of one to three or two $\mathrm{H}$ atoms (1-3 Da),

580 indicative of both inter- or intramolecular cross-links (Table S14). Also in the absence of AscH',

581 the Western blotting data suggest that inter-molecular linkages are more prevalent, with most of

582 the staining detected in oligomer bands. However, in the presence of $\mathrm{AscH}^{-}$, only very low-

583 intensity dityrosine bands as detected by Western blotting (Fig. 5B, lanes 6 - 10). The amino acid

584 analysis (Fig. 3) also suggest that Met sulfoxide may not be the final product arising from

585 oxidation of this residue in the presence of $\mathrm{AscH}^{-}$, though with only slow conversion of Met

586 sulfoxide (+16 Da) to sulfone (+32 Da). The MS results from the $0.1,5$ and 15 min samples in

587 the presence of $\mathrm{AscH}^{-}$(Fig. 7, Table S15) indicate that there are $1-6$ oxygen species attached to

588 protonated $\alpha-S N$. Even at 0.1 minute oxidation the highest intensity is the peak with $m / z$ values

589 of $1036.6(+47 \mathrm{Da} ;+3 \mathrm{O}-1 \mathrm{H})$, consistent with very rapid conversion of Met residues to Met

590 sulfoxide.

591 4.7. Physiological relevance of copper-ion catalyzed oxidation of $\alpha-S N$ in the absence and 592 presence of $\mathrm{AscH}^{-}$

593

594 The pathogenesis of Parkinson's disease includes compromised cell membrane integrity,

mitochondrial stress, synaptic dysfunction, and general cellular toxicity [84]. However, the 
Running title: Copper-ion catalyzed oxidation of $\alpha$-synuclein

597 intermediates during the self-assembly of $\alpha$-SN, and toxic effects of such prefibrillar been have 598 reported [85].

$\underline{\text { Collectively, our studies shows that brief exposure of } \alpha \text {-SN to a } \mathrm{Cu}^{2+} / \mathrm{H}_{2} \underline{\mathrm{O}}_{2} \text { system }}$ 600 without $\mathrm{AscH}^{-}$leads to a rapid and complete oxidation of two crucial amino acid residues; i.e.; 601 methionine and tyrosine (Figs. 3A and 3B), which are implicated in the toxicity of $\alpha-S N$. 602 Oxidation of methionine and tyrosine residues are known to inhibit fibrillation of $\alpha$-SN and 603 thereby formation of stable soluble $\alpha$-SN oligomers [86]; which are central to PD pathogenesis 604 [85]. In vitro and in vivo studies have shown that the oxidation of methionine in $\alpha$-SN i) impairs 605 its degradation by the 20S proteasome [87], ii) decreases its affinity for membranes [88], and iii) 606 promotes the formation of cytotoxic $\alpha$-SN oligomers [89]. Furthermore, C-terminal methionine 607 sulfoxides are suggested to reduce the phosphorylation of Tyr125 by tyrosine kinase Fyn; which 608 has been linked to age- and disease-dependent decline of Tyr125 phosphorylation both in a 609 Drosophila PD model and in humans [90]. Previous work has also revealed that Lewy bodies in 610 PD patient brain tissues contain dityrosine cross-linked $\alpha$-SN oligomers [26]. Studies using 611 animal models have suggested that the dityrosine cross-linked dimers may play an important role 612 in oligomer toxicity [91]. Furthermore, seeding experiments with dityrosine cross-linked dimers 613 are found to accelerate $\alpha$-SN fibril growth indicating dityrosine cross-linked dimeric $\alpha$-SN 614 species to rate-limiting step in the nucleation of $\alpha$-syn fibrils [92]. In line with previous 615 observations, our data demonstrate the formation of SDS- and heat-stable dityrosine cross-linked $616 \underline{\alpha-S N}$ oligomers and the oxidation of methionines within 5 min (Figs. 4 and 5). These species are 617 potential early intermediates in the formation of toxic prefibrillar $\alpha$-SN oligomers. When $\alpha-\mathrm{SN}$ was exposed to the $\mathrm{Cu}^{2+} / \mathrm{H}_{2} \underline{\mathrm{O}}_{2} / \mathrm{AscH}^{-}$mixture, more limited oxidation of two 619 Met residues and one Tyr residue was detected (Fig. 3C and 3D), with a near total absence of 620 dityrosine-containing cross-linked dimer, trimer, tetramer, and pre-fibrillar oligomer bands as 
Running title: Copper-ion catalyzed oxidation of $\alpha$-synuclein

621 judged by SDS-PAGE and Western blot analysis (Figs. 4C and 5B). However, significant His-50

622 oxidation was detected under these conditions in a site-specific manner (Fig. 3D). To counteract

623 the oxidative imbalance leading to intracellular damages to the proteins, several subcellular

624 compartments contain sophisticated repair machinery including $\mathrm{AscH}^{-}[93,94]$. AscH is a strong

625 reducing agent, which can reduce transition metal ions including $\mathrm{Cu}^{2+}$. AscH is also known to act

626 as pro- and antioxidant depending on its concentrations [75, 93]. Remarkably, when $\alpha$-SN was

627 exposed to $\mathrm{Cu}^{2+} / \mathrm{H}_{2} \mathrm{O}_{2} / \mathrm{AscH}^{-}$system, oxidation of only two methionines was observed (Fig. 3C).

628 Met-5 and Met-1 at the N-terminus constitutes the major $\mathrm{Cu}^{2+}$ binding site of $\alpha$-SN [80]. Thus

629 the presence of $\mathrm{AscH}^{-}$in the reaction (condition 5) may lead to the site-specific oxidation of Met-

6305 and Met-1. However, at any given time interval only two Met were oxidized to Met sulfoxide

631 (Fig. 3C). AscH ${ }^{-}$is also known to efficiently repair protein-thiol and protein-Tyr radicals [95,

632 96]. At this point, we can only speculate that the two C-terminal Met (Met-116 and Met-127)

633 remain fully oxidized as Met sulfoxide. This observation is further supported by a previous study

634 where intracellular repair enzyme, methionine sulfoxide reductase (MSR) failed to repair Met-

635116 and Met-127 [70]. Irrespective of the $\mathrm{AscH}^{-}$concentration used in this study, the

636 experiments showed consumption of on average about one Tyr residue (Fig. 3D, Fig. S13B). This

637 observation indicates that i) the oxidation of Tyr residues may not involve site-specific reactions

638 as these residues are not involved in copper coordination [97] and ii) $\mathrm{AscH}^{-}$may prevent

639 oxidative damage to specific Tyr residues. It has been shown that Tyr phenoxyl radicals (reaction

640 VI), a precursor of dityrosine, react rapidly with both the superoxide radical anion (reaction VII)

$641[98,99]$ and also $\mathrm{AscH}^{-}$(reaction VIII) [100]. Thus, $\mathrm{AscH}^{-}$can both accelerate the decay of Tyr

642 phenoxyl radicals consistent with the repair of protein radicals and inhibit the formation of these

643 species in a concentration-dependent manner [94]. These reactions are consistent with the

644 complete disappearance of dityrosine formation in the presence of $\mathrm{AscH}^{-}$[99]. 
Running title: Copper-ion catalyzed oxidation of $\alpha$-synuclein

645

646

647

648

649

650

651

652

653

654

655

656

657

658

659

660

661

662

663

664

665

667 666 that oxidative stress plays a mechanistic role in the onset/progression of PD and related 668 the literature supports an antioxidant effect in vivo. Anti-oxidant effects of AscH ${ }^{-}$could, decrease

(VI) $\underline{\mathrm{Tyr}-\mathrm{H}+\mathrm{HO}^{\circ} \rightarrow \mathrm{Tyr}^{\bullet}+\mathrm{H}_{2} \mathrm{O}}$

(VII) $\underline{\mathrm{Tyr}}+\mathrm{O}_{2}{ }^{-\bullet}+\mathrm{H}^{+} \rightarrow \mathrm{Tyr}-\mathrm{H}+\mathrm{O}_{2}$

(VIII) $\mathrm{TyrO}^{\bullet}+\mathrm{AscH}^{-} \rightarrow \mathrm{TyrOH}+\mathrm{Asc}^{-\bullet}$

52

In summary, this is the first systematic study providing experimental evidence of early

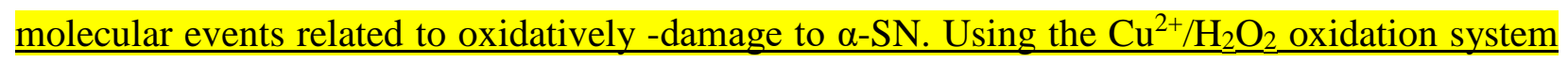
we have demonstrated that both Met and Tyr oxidation precedes significant carbonyl formation and the oxidation of Met and Tyr residues can be observed as early as 5 min; leading to a rapid Met sulfoxide formation and dityrosine cross-linked pre-fibrillar oligomer assemblies. Such prefibrillar species of $\alpha$-SN have been suggested to exert damaging effects, via both intra- and extracellular mechanisms [85]. In contrast, the $\mathrm{Cu}^{2+} / \mathrm{H}_{2} \mathrm{O}_{2} / \mathrm{AscH}^{-}$oxidation system resulted in an "oxidative burst" with early carbonylation and site-specific oxidation of His-50. However, the dityrosine cross-linked pre-fibrillar oligomer assemblies were completely inhibited in the presence of $\mathrm{AscH}^{-}$and only limited amounts of Met sulfoxide was formed. This indicates a potential protective role of $\mathrm{AscH}^{-}$against oxidatively generated damage to $\alpha$-SN. Our results highlight the early events leading to $\alpha$-SN oxidation and may advance our understanding of the pathogenesis of other protein conformational diseases such as Alzheimer's and Prion disease. $\underline{\text { Taken together, our data presented here using } \mathrm{Cu}^{2+} / \mathrm{H}_{2} \underline{\mathrm{O}}_{2} \text { oxidation provide increasing evidence }}$ 667 synucleinopathies. Although $\mathrm{AscH}^{-}$can show both pro- and anti-oxidant effects, the majority of 
Running title: Copper-ion catalyzed oxidation of $\alpha$-synuclein

669 Cu-mediated oxidative damage to $\alpha-\mathrm{SN}$, and may be an effective strategy against PD and related 670 disorders $[93,94]$. Further studies are underway to investigate the transient formation of $\alpha$-SN 671 dimers and oligomers to assess their toxicity and cell permeability.

672

\section{Acknowledgements}

674 We gratefully acknowledge financial support from the Danish Council for Independent Research 675 Technology and Production Sciences (Grant no.: DFF| FTP 4005-00082 to IMM). MJD 676 gratefully acknowledge financial support from the Novo Nordisk Foundation (Grant no.: NNF 677 13OC0004294). MKT, MJB and MJD also acknowledge financial support from the Lundbeck 678 Foundation postdoctoral fellowship to MKT (Grant no.: R231-2016-3276). 
Running title: Copper-ion catalyzed oxidation of $\alpha$-synuclein
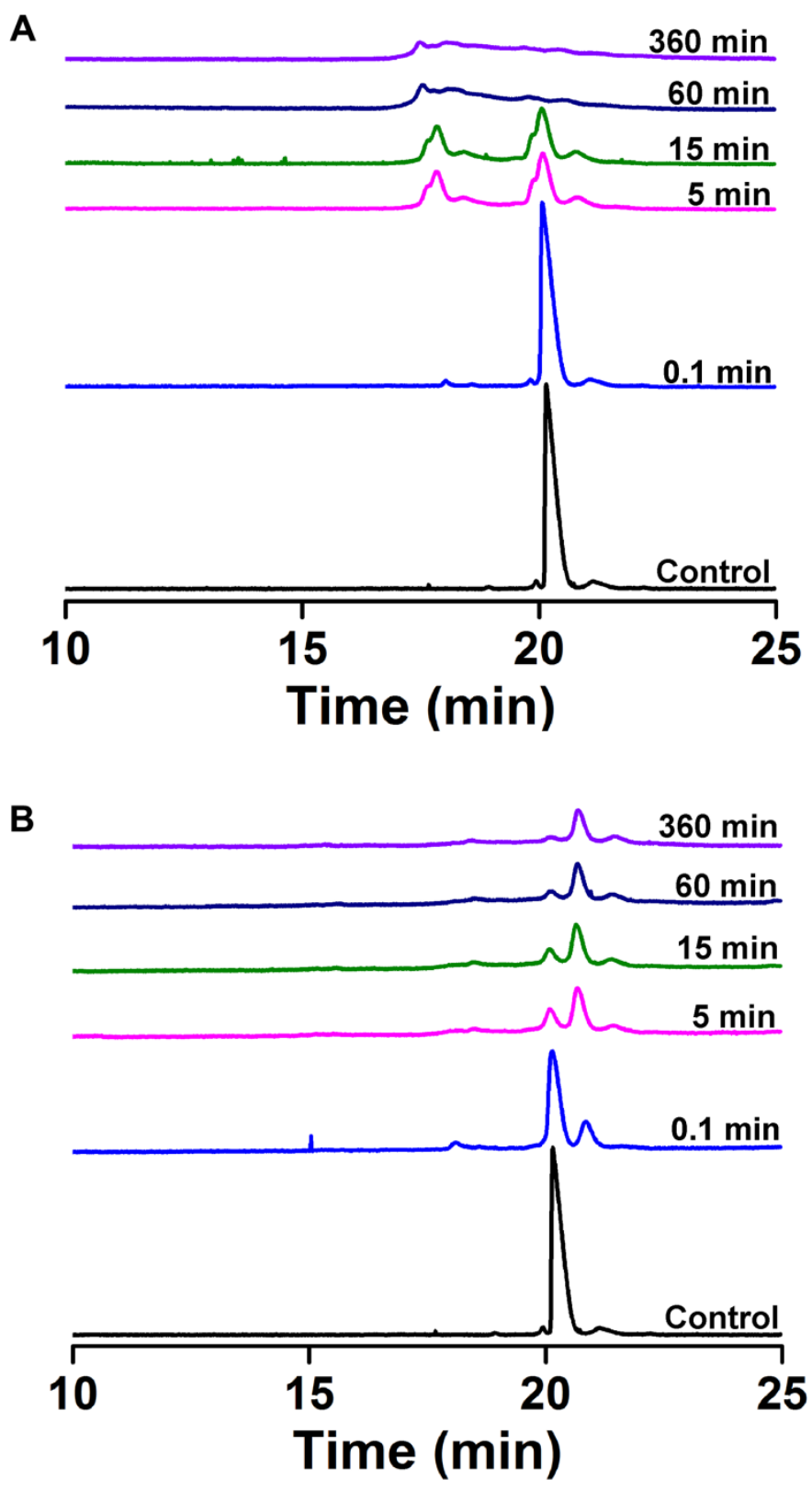

681 Figure 1. $\mathrm{Cu}^{2+} / \mathrm{H}_{2} \mathrm{O}_{2}-$ mediated oxidation of $\boldsymbol{\alpha}-\mathrm{SN}$ in the absence and presence of ascorbate (AscH-).

682 Overlayed time-dependent capillary electrophoresis (CE) electropherograms of control and oxidized $\alpha-$ 683 SN. (A) $57.6 \mu \mathrm{M}$ of $\alpha-\mathrm{SN}$ subjected to oxidation using a $\mathrm{Cu}^{2+} / \mathrm{H}_{2} \mathrm{O}_{2}$ system with a molar ratio of 1:2.3:7.8 684 between $\alpha-\mathrm{SN}: \mathrm{Cu}^{2+}: \mathrm{H}_{2} \mathrm{O}_{2}$ (Condition 1). (B) $57.6 \mu \mathrm{M}$ of $\alpha-\mathrm{SN}$ subjected to $\mathrm{Cu}^{2+} / \mathrm{H}_{2} \mathrm{O}_{2} / \mathrm{AscH}^{-}$oxidation 685 using a molar ratio of 1:2.3:7.8:7.8 between $\alpha-\mathrm{SN}: \mathrm{Cu}^{2+}: \mathrm{H}_{2} \mathrm{O}_{2}: \mathrm{AscH}^{-}$(Condition 5). Except for the 0.1 686 min sample, all other reaction mixtures were incubated at $37^{\circ} \mathrm{C}$ for the time shown in the figure. 
Running title: Copper-ion catalyzed oxidation of $\alpha$-synuclein
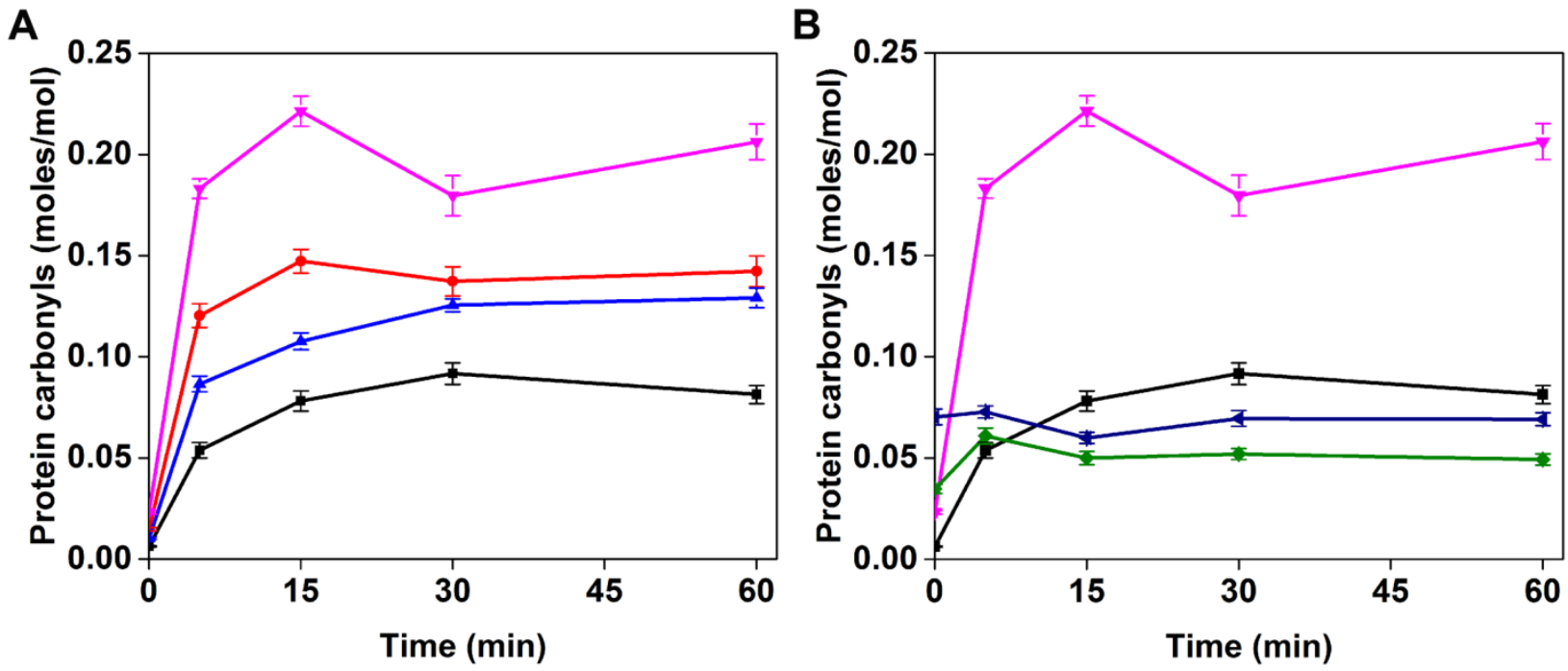

Fig. 2. Time-dependent formation of carbonyls on $\alpha-\mathrm{SN}$ induced by $\mathrm{Cu}^{2+} / \mathrm{H}_{2} \mathrm{O}_{2}$-mediated oxidation

689 in the absence and presence of AscH- $^{-}$Time-course of protein carbonyl formation resulting from 690 oxidation of $\alpha-\mathrm{SN}(57.6 \mu \mathrm{M})$ in the absence and presence of $\mathrm{AscH}^{-}$; (A) Condition 1 (black) with molar 691 ratio of 1:2.3:7.8:0, condition 2 (red) with molar ratio of 1:4.7:7.8:0, Condition 3 (blue) with molar ratio of 692 1:2.3:15.6:0, Condition 4 (pink) with molar ratio of 1:4.7:15.6:0. (B) $\mathrm{Cu}^{2+} / \mathrm{H}_{2} \mathrm{O}_{2} / \mathrm{AscH}^{-}$mediated oxidation 693 (condition 5) (green) with molar ratios 1:2.3:7.8:7.8, and condition 6 (blue) with molar ratio of 694 1:4.7:15.6:15.6. Protein carbonyl levels are given as moles carbonyl/mole protein, and the data points and 695 error bars represent the means and standard deviation of three independent experiments. Except for 0.1 696 min samples, all other reaction mixtures were incubated at $37^{\circ} \mathrm{C}$ for the time intervals shown. 
Running title: Copper-ion catalyzed oxidation of $\alpha$-synuclein
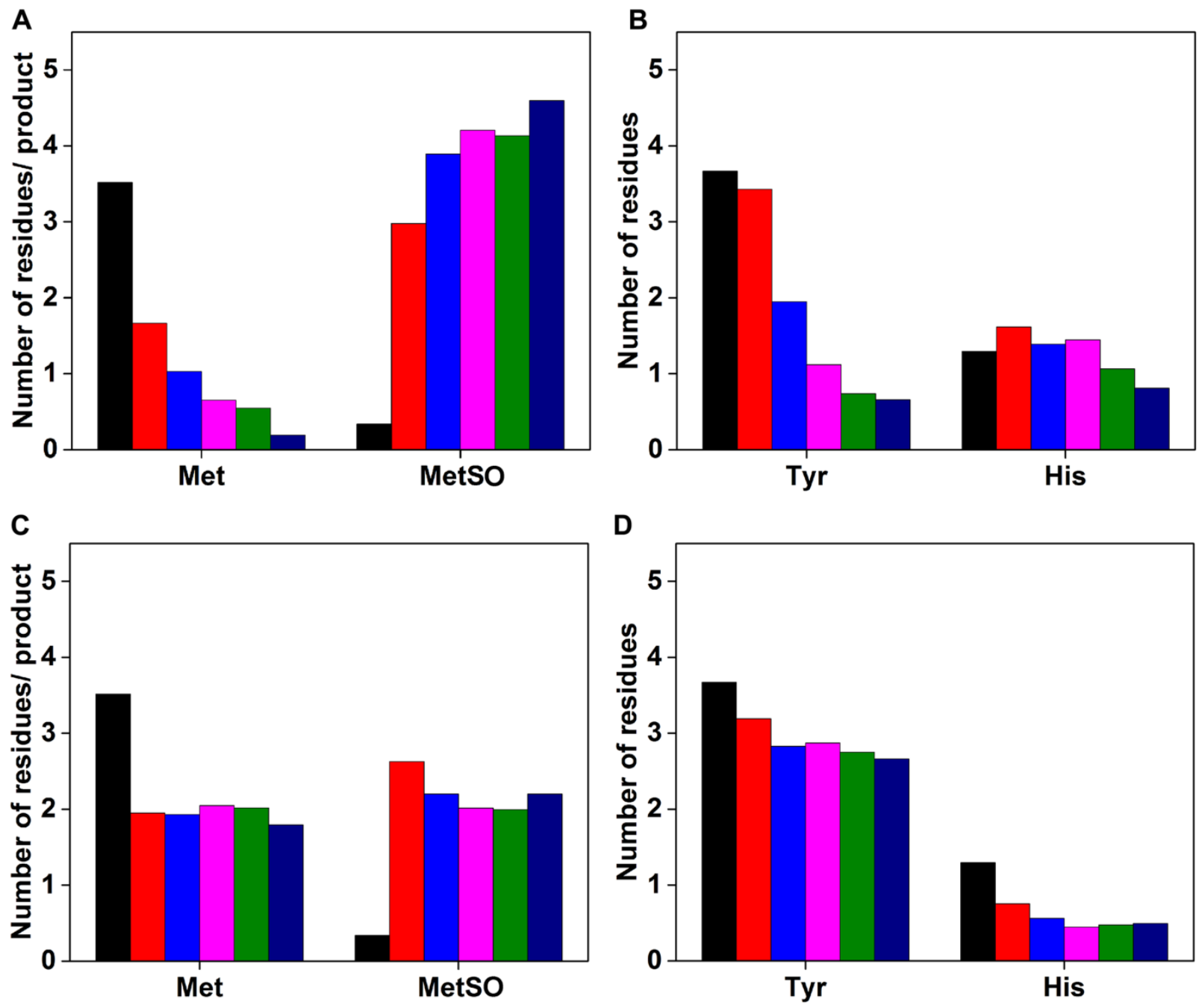

Fig. 3. Changes in composition of Met, Tyr, His and Met sulfoxide on $\alpha-\mathrm{SN}$ induced by $\mathrm{Cu}^{2+} / \mathrm{H}_{2} \mathrm{O}_{2-}$ mediated oxidation in the absence and presence of AscH'. Bar graphs showing normalized values for the loss of Met, Tyr, His and production of Met sulfoxide. (A and B) Condition 1 with molar ratio of 1:2.3:7.8:0 between $\alpha-\mathrm{SN}: \mathrm{Cu}^{2+}: \mathrm{H}_{2} \mathrm{O}_{2}$. (C and D) Condition 5 with molar ratio of 1:2.3:7.8:7.8 between $\alpha-\mathrm{SN}: \mathrm{Cu}^{2+}: \mathrm{H}_{2} \mathrm{O}_{2}: \mathrm{AscH}^{-}$. Data shown are for five-time points $0.1 \mathrm{~min}$ (red), 5 min (blue), 15 min (pink), 60 min (green), and 360 min (navy blue), whereas black color bar represents composition of respective residues and Met sulfoxide in the native $\alpha-\mathrm{SN}$; for details, see Materials and methods. Except for 0.1 min sample, all other reaction mixtures were incubated at $37^{\circ} \mathrm{C}$ for the time intervals indicated. 
Running title: Copper-ion catalyzed oxidation of $\alpha$-synuclein

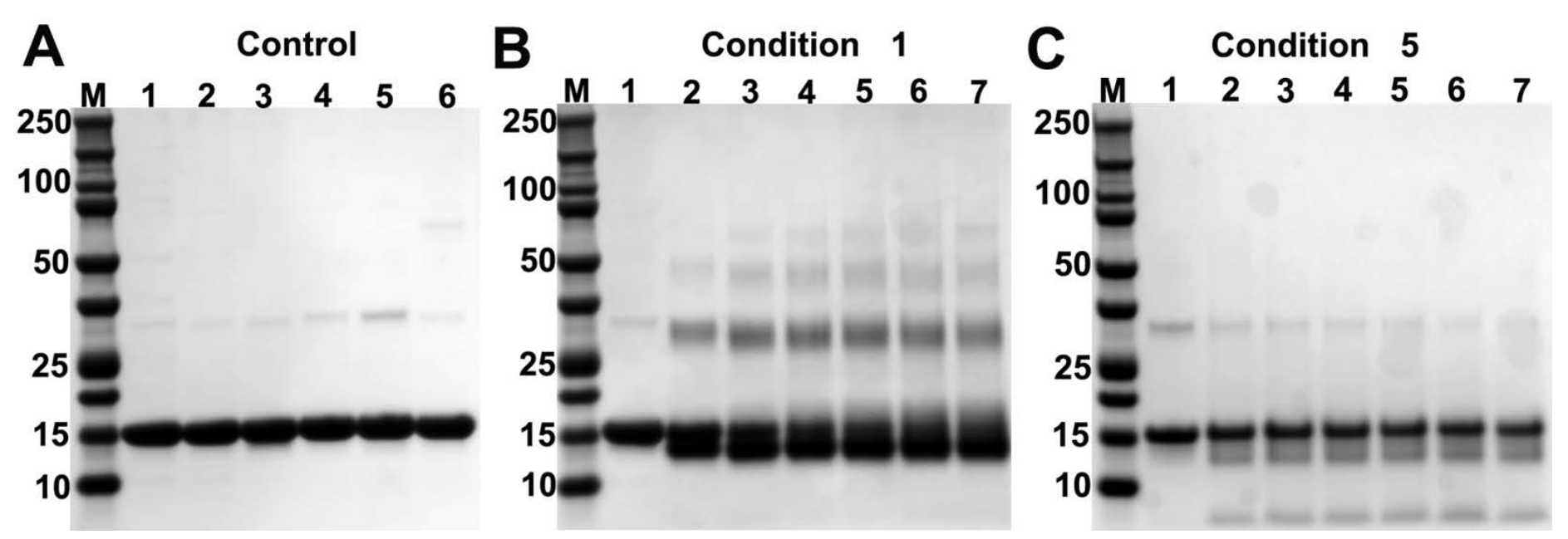

Fig. 4. SDS-PAGE analyses of control and oxidized $\alpha-\mathrm{SN}$ exposed to various concentrations of $\mathrm{Cu}^{2+}$ and $\mathrm{H}_{2} \mathrm{O}_{2}$, without and with

AscH'. Samples were prepared as indicated in the Materials and methods. (A) Control samples; lane M, molecular mass markers; lane - 1, native $\alpha-\mathrm{SN}$; lane $-2, \alpha-\mathrm{SN}$ incubated at $37^{\circ} \mathrm{C}$ for $360 \mathrm{~min}$; lane $-3, \alpha-\mathrm{SN}$ incubated with $\mathrm{Cu}^{2+}$ at $37^{\circ} \mathrm{C}$ for 360 min; lane $-4, \alpha-\mathrm{SN}$ incubated with $\mathrm{H}_{2} \mathrm{O}_{2}$ at $37^{\circ} \mathrm{C}$ for 360 min; lane - 5, $\alpha-\mathrm{SN}$ incubated with $\mathrm{AscH}^{-}$at $37^{\circ} \mathrm{C}$ for 360 min; lane -6, $\alpha-\mathrm{SN}$ incubated with EDTA at $37^{\circ} \mathrm{C}$ for $360 \mathrm{~min}$. (B) Oxidation with condition 1, and (C) oxidation with condition 5 with the following samples: lane M, molecular mass markers; lane -1 , oxidation for 0.1 min; lane -2 , oxidation for 5 min; lane -3 , oxidation for 15 min; lane -4 , oxidation for 30 min; lane - 5, oxidation for $60 \mathrm{~min}$; lane - 6, oxidation for $180 \mathrm{~min}$; lane - 7, oxidation for $360 \mathrm{~min}$. 
Running title: Copper-ion catalyzed oxidation of $\alpha$-synuclein
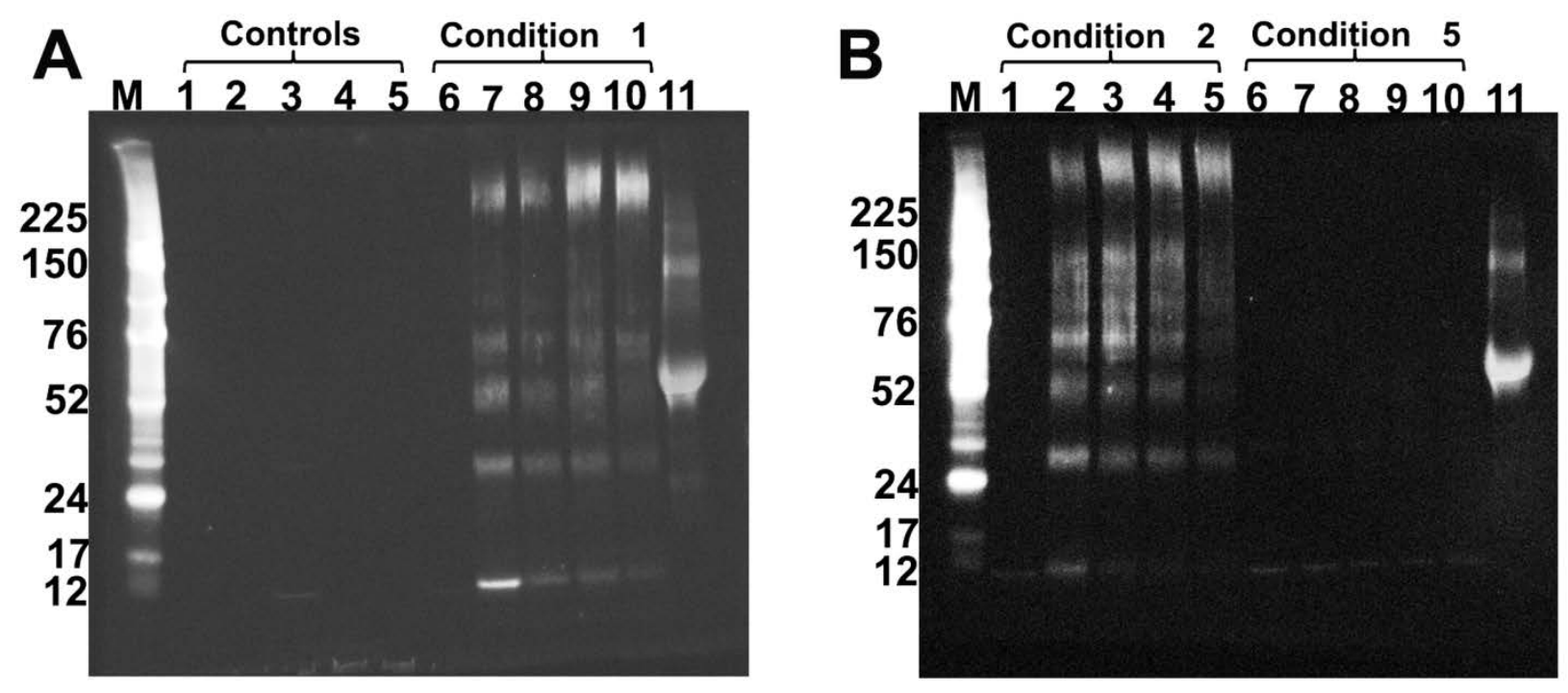

Fig. 5. Detection of dityrosine on oxidized $\alpha-S N$ by Western-blotting. Oxidized $\alpha-S N$ samples $(22 \mu \mathrm{M})$ were electrophoresed and transferred to nitrocellulose membranes as described in the Materials and methods. (A) Controls organized as follows; lane $\mathrm{M}$ - molecular mass markers; lane -1 , native $\alpha-\mathrm{SN}$; lane - 2, $\alpha-\mathrm{SN}$ incubated at $37^{\circ} \mathrm{C}$ for $360 \mathrm{~min}$; lane $-3, \alpha-\mathrm{SN}$ incubated with $\mathrm{Cu}^{2+}$ at $37{ }^{\circ} \mathrm{C}$ for $360 \mathrm{~min}$; lane $-4, \alpha-\mathrm{SN}$ incubated with $\mathrm{H}_{2} \mathrm{O}_{2}$ at $37{ }^{\circ} \mathrm{C}$ for 360 min; lane $-5, \alpha-\mathrm{SN}$ incubated with $\mathrm{AscH}^{-}$at $37{ }^{\circ} \mathrm{C}$ for 360 min. Lanes 6 - 10 are samples of $\alpha-S N$ oxidized under condition 1 for 0.1 min, 5, 15, 60 and 360 min, respectively. (B) Lanes 1-5: as lanes 6-10 of (a) except with oxidation under condition 2 (higher $\mathrm{Cu}^{2+}$ concentration) for $0.1 \mathrm{~min}, 5,15,60$ and $360 \mathrm{~min}$. Lanes 6-10: with oxidation under condition 5 (presence of $\mathrm{AscH}^{-}$) and oxidation for $0.1 \mathrm{~min}, 5,15,60$ and $360 \mathrm{~min}$. Lane 11 in both images is a positive control consisting of $3 \mathrm{mg} \mathrm{mL}^{-1}$ glucose-6-phosphate dehydrogenase exposed to ${ }^{1} \mathrm{O}_{2}$ generated using 10 $\mu \mathrm{M}$ Rose Bengal and visible light, for $90 \mathrm{~min}$ at $4^{\circ} \mathrm{C}[48]$. 
Running title: Copper-ion catalyzed oxidation of $\alpha$-synuclein

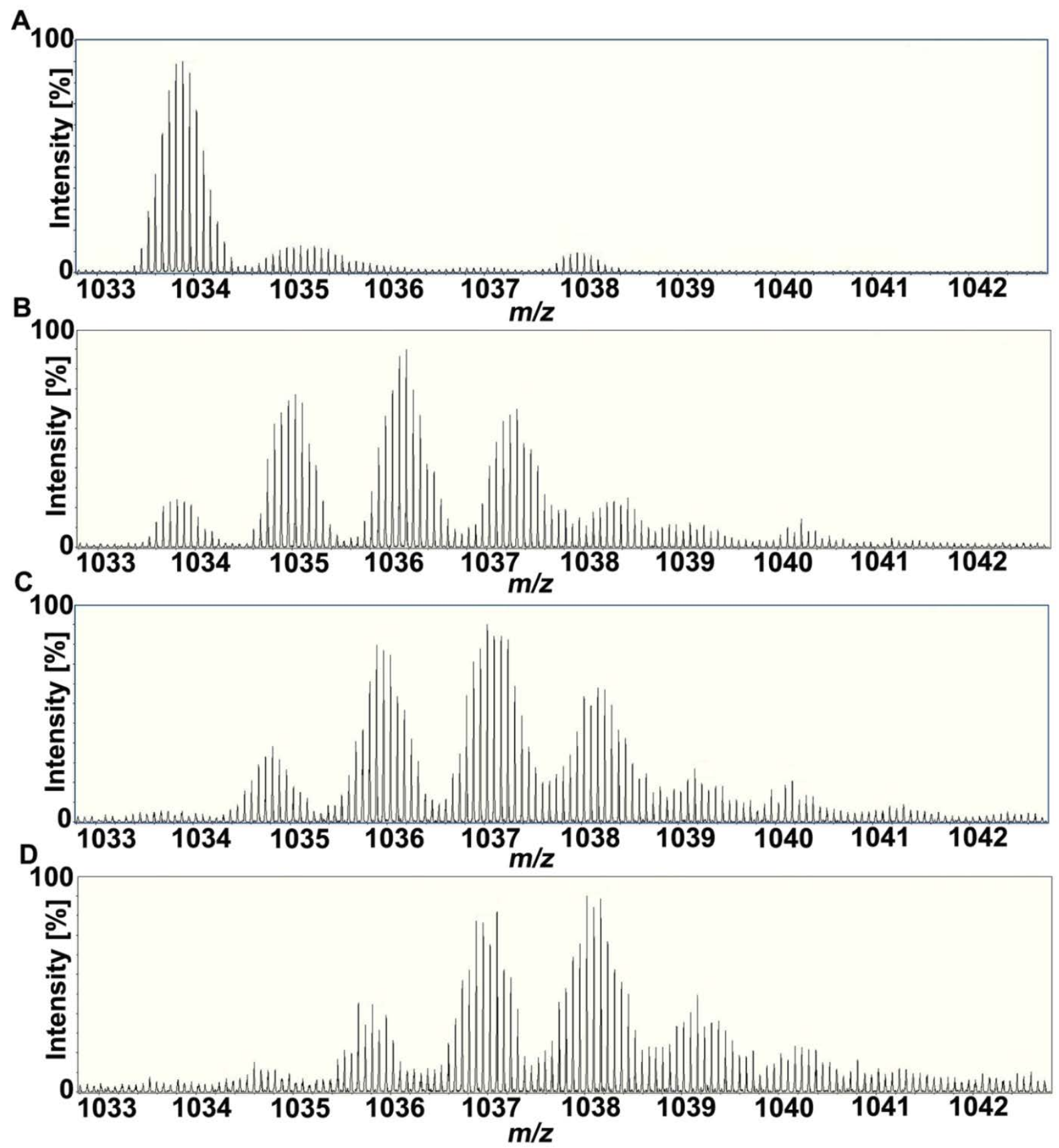

Fig. 6. Positive ion ESI-MS spectra of $\mathrm{Cu}^{2+} / \mathrm{H}_{2} \mathrm{O}_{2}-$ oxidized $\alpha-\mathrm{SN}$ in the absence of AscH- (condition 1) with using molar ratios of $1: 2.3: 7.8$ for $\alpha-\mathrm{SN}: \mathrm{Cu}^{2+}: \mathrm{H}_{2} \mathrm{O}_{2}$. (A) Native $\alpha-\mathrm{SN}$, (B) oxidized for 0.1 min, (C) oxidized for $5 \mathrm{~min}$ and, (D) oxidized for $15 \mathrm{~min}$. The $\mathrm{m} / \mathrm{z}$ values indicated are monoisotopic masses. 
Running title: Copper-ion catalyzed oxidation of $\alpha$-synuclein

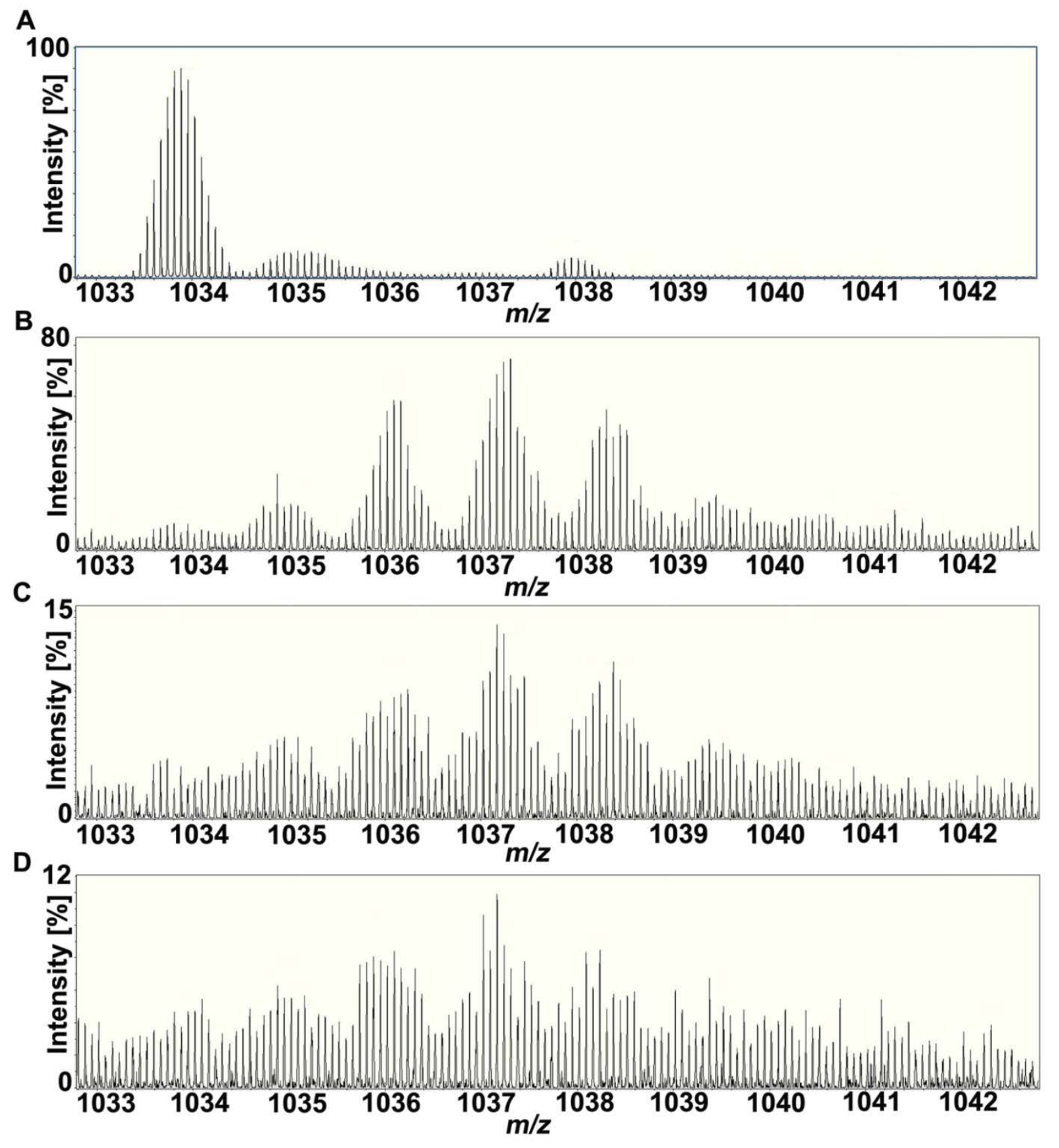

Fig. 7. Positive ion ESI-MS spectra of $\mathrm{Cu}^{2+} / \mathrm{H}_{2} \mathrm{O}_{2}-$ oxidized $\alpha-\mathrm{SN}$ in the presence of $\mathrm{AscH}^{-}$(condition 5) using molar ratios of $1: 2.3: 7.8: 7.8$ between $\alpha-\mathrm{SN}$ : $\mathrm{Cu}^{2+}: \mathrm{H}_{2} \mathrm{O}_{2}$ : AscH- (A) Native $\alpha-\mathrm{SN}$, (B) oxidized for $0.1 \mathrm{~min}$, (C) oxidized for $5 \mathrm{~min}$ and, (D) oxidized for $15 \mathrm{~min}$. The $\mathrm{m} / \mathrm{z}$ values indicated are monoisotopic masses. 
Running title: Copper-ion catalyzed oxidation of $\alpha$-synuclein

Table 1: Concentrations and molar ratios of reagents employed to initiate oxidation of $\alpha-S N$.

\begin{tabular}{|c|c|c|c|c|c|}
\hline \multirow{2}{*}{ Samples } & \multicolumn{3}{|c|}{ Final concentrations in reaction mixture $(\boldsymbol{\mu M})$} & Molar ratios \\
\cline { 2 - 6 } & $\boldsymbol{\alpha}-\mathbf{S N}$ & $\mathbf{C u C l}_{\mathbf{2}}$ & $\mathbf{H}_{\mathbf{2}} \mathbf{O}_{\mathbf{2}}$ & $\mathbf{A s c H}$ & $\left(\boldsymbol{\alpha}-\mathbf{S N}: \mathbf{C u}^{2+}: \mathbf{H}_{\mathbf{2}} \mathbf{O}_{2}: \mathbf{A s c H}^{-}\right)$ \\
\hline Condition 1 & 57.6 & 135 & 450 & 0 & $1: 2.3: 7.8: 0$ \\
\hline Condition 2 & 57.6 & 270 & 450 & 0 & $1: 4.7: 7.8: 0$ \\
\hline Condition 3 & 57.6 & 135 & 900 & 0 & $1: 2.3: 15.6: 0$ \\
\hline Condition 4 & 57.6 & 270 & 900 & 0 & $1: 4.7: 15.6: 0$ \\
\hline Condition 5 & 57.6 & 135 & 450 & 450 & $1: 2.3: 7.8: 7.8$ \\
\hline Condition 6 & 57.6 & 270 & 900 & 900 & $1: 4.7: 15.6: 15.6$ \\
\hline
\end{tabular}

Reaction set-up for five control samples at two-time intervals (0.1 min and $360 \mathrm{~min}$ ) are described in Table S2.

2 mM EDTA was added to terminate the MCO reaction after each time interval as described in the Materials and methods. 
Running title: Copper-ion catalyzed oxidation of $\alpha$-synuclein

\section{References:}

[1] J.K. Andersen, Oxidative stress in neurodegeneration: cause or consequence?, Nat Med 10 Suppl (2004) S1825.

[2] K.J. Barnham, C.L. Masters, A.I. Bush, Neurodegenerative diseases and oxidative stress, Nat Rev Drug Discov 3(3) (2004) 205-14.

[3] B.C. Dickinson, C.J. Chang, Chemistry and biology of reactive oxygen species in signaling or stress responses, Nat Chem Biol 7(8) (2011) 504-11.

[4] C. Nathan, A. Cunningham-Bussel, Beyond oxidative stress: an immunologist's guide to reactive oxygen species, Nat Rev Immunol 13(5) (2013) 349-61.

[5] M.J. Davies, Protein oxidation and peroxidation, Biochem J 473(7) (2016) 805-25.

[6] B.I. Giasson, J.E. Duda, I.V. Murray, Q. Chen, J.M. Souza, H.I. Hurtig, H. Ischiropoulos, J.Q. Trojanowski, V.M. Lee, Oxidative damage linked to neurodegeneration by selective alpha-synuclein nitration in synucleinopathy lesions, Science 290(5493) (2000) 985-9.

[7] D.A. Butterfield, Amyloid $\beta$-peptide [1-42]-associated free radical-induced oxidative stress and neurodegeneration in Alzheimer's disease brain: mechanisms and consequences, Curr Med Chem 10(24) (2003) 2651-9.

[8] M.K. Tiwari, K.P. Kepp, $\beta$-Amyloid pathogenesis: Chemical properties versus cellular levels, Alzheimers Dement 12(2) (2016) 184-194.

[9] R.J. Ferrante, S.E. Browne, L.A. Shinobu, A.C. Bowling, M.J. Baik, U. MacGarvey, N.W. Kowall, R.H. Brown, M.F. Beal, Evidence of Increased Oxidative Damage in Both Sporadic and Familial Amyotrophic Lateral Sclerosis, J Neurochem 69(5) (1997) 2064-2074.

[10] J. Gil-Mohapel, P.S. Brocardo, B.R. Christie, The role of oxidative stress in Huntington's disease: are antioxidants good therapeutic candidates?, Curr Drug Targets 15(4) (2014) 454-68.

[11] M. Guentchev, T. Voigtlãander, C. Haberler, M.H. Groschup, H. Budka, Evidence for Oxidative Stress in Experimental Prion Disease, Neurobiol Dis 7(4) (2000) 270-273.

[12] S. Gandhi, N.W. Wood, Genome-wide association studies: the key to unlocking neurodegeneration?, Nat Neurosci 13(7) (2010) 789-94.

[13] C. Henchcliffe, M.F. Beal, Mitochondrial biology and oxidative stress in Parkinson disease pathogenesis, Nat Clin Pract Neurol 4(11) (2008) 600-9.

[14] S. Papapetropoulos, N. Adi, J. Ellul, A.A. Argyriou, E. Chroni, A prospective study of familial versus sporadic Parkinson's disease, Neurodegener Dis 4(6) (2007) 424-7.

[15] M.G. Spillantini, R.A. Crowther, R. Jakes, N.J. Cairns, P.L. Lantos, M. Goedert, Filamentous $\alpha$-Synuclein inclusions link multiple system atrophy with Parkinson's disease and dementia with Lewy bodies, Neurosci Lett 251(3) (1998) 205-8.

[16] M.G. Spillantini, R.A. Crowther, R. Jakes, M. Hasegawa, M. Goedert, $\alpha$-Synuclein in filamentous inclusions of Lewy bodies from Parkinson's disease and dementia with lewy bodies, Proc Natl Acad Sci U S A 95(11) (1998) 6469-73. 
Running title: Copper-ion catalyzed oxidation of $\alpha$-synuclein

[17] L. Maroteaux, J.T. Campanelli, R.H. Scheller, Synuclein: a neuron-specific protein localized to the nucleus and presynaptic nerve terminal, J Neurosci 8(8) (1988) 2804-15.

[18] T. Yasuda, Y. Nakata, H. Mochizuki, $\alpha$-Synuclein and neuronal cell death, Mol Neurobiol 47(2) (2013) 466-83.

[19] O. Marques, T.F. Outeiro, Alpha-synuclein: from secretion to dysfunction and death, Cell Death Dis 3 (2012) e350.

[20] V.N. Uversky, J. Li, A.L. Fink, Evidence for a partially folded intermediate in $\alpha$-Synuclein fibril formation, J Biol Chem 276(14) (2001) 10737-44.

[21] P.P. Michel, E.C. Hirsch, S. Hunot, Understanding Dopaminergic Cell Death Pathways in Parkinson Disease, Neuron 90(4) (2016) 675-91.

[22] A. Umeno, V. Biju, Y. Yoshida, In vivo ROS production and use of oxidative stress-derived biomarkers to detect the onset of diseases such as Alzheimer's disease, Parkinson's disease, and diabetes, Free Radic Res 51(4) (2017) 413-427.

[23] C. Zhou, Y. Huang, S. Przedborski, Oxidative stress in Parkinson's disease: a mechanism of pathogenic and therapeutic significance, Ann N Y Acad Sci 1147 (2008) 93-104.

[24] V.N. Uversky, G. Yamin, P.O. Souillac, J. Goers, C.B. Glaser, A.L. Fink, Methionine oxidation inhibits fibrillation of human $\alpha$-Synuclein in vitro, FEBS Lett 517(1-3) (2002) 239-44.

[25] J.M. Souza, B.I. Giasson, Q. Chen, V.M. Lee, H. Ischiropoulos, Dityrosine cross-linking promotes formation of stable $\alpha$-synuclein polymers. Implication of nitrative and oxidative stress in the pathogenesis of neurodegenerative synucleinopathies, J Biol Chem 275(24) (2000) 18344-9.

[26] Y.K. Al-Hilaly, L. Biasetti, B.J. Blakeman, S.J. Pollack, S. Zibaee, A. Abdul-Sada, J.R. Thorpe, W.F. Xue, L.C. Serpell, The involvement of dityrosine crosslinking in $\alpha$-synuclein assembly and deposition in Lewy Bodies in Parkinson's disease, Sci Rep 6 (2016) 39171.

[27] D.T. Dexter, A. Carayon, F. Javoy-Agid, Y. Agid, F.R. Wells, S.E. Daniel, A.J. Lees, P. Jenner, C.D. Marsden, Alterations in the levels of iron, ferritin and other trace metals in Parkinson's disease and other neurodegenerative diseases affecting the basal ganglia, Brain 114 ( Pt 4) (1991) 1953-75.

[28] D.T. Dexter, F.R. Wells, A.J. Lees, F. Agid, Y. Agid, P. Jenner, C.D. Marsden, Increased nigral iron content and alterations in other metal ions occurring in brain in Parkinson's disease, J Neurochem 52(6) (1989) 1830-6.

[29] H.S. Pall, A.C. Williams, D.R. Blake, J. Lunec, J.M. Gutteridge, M. Hall, A. Taylor, Raised cerebrospinalfluid copper concentration in Parkinson's disease, Lancet 2(8553) (1987) 238-41.

[30] K.J. Barnham, A.I. Bush, Biological metals and metal-targeting compounds in major neurodegenerative diseases, Chem Soc Rev 43(19) (2014) 6727-49.

[31] G. Yamin, C.B. Glaser, V.N. Uversky, A.L. Fink, Certain metals trigger fibrillation of methionine-oxidized $\alpha$-synuclein, J Biol Chem 278(30) (2003) 27630-5.

[32] R.M. Rasia, C.W. Bertoncini, D. Marsh, W. Hoyer, D. Cherny, M. Zweckstetter, C. Griesinger, T.M. Jovin, C.O. Fernandez, Structural characterization of copper(II) binding to $\alpha$-synuclein: Insights into the bioinorganic chemistry of Parkinson's disease, Proc Natl Acad Sci U S A 102(12) (2005) 4294-9.

[33] T.S. Ulmer, A. Bax, Comparison of structure and dynamics of micelle-bound human $\alpha$-synuclein and Parkinson disease variants, J Biol Chem 280(52) (2005) 43179-87. 
Running title: Copper-ion catalyzed oxidation of $\alpha$-synuclein

[34] L. Breydo, J.W. Wu, V.N. Uversky, $\alpha$-Synuclein misfolding and Parkinson's disease, Biochim Biophys Acta 1822(2) (2012) 261-85.

[35] J.C. Lee, H.B. Gray, J.R. Winkler, Copper(II) binding to $\alpha$-synuclein, the Parkinson's protein, J Am Chem Soc 130(22) (2008) 6898-9.

[36] O. Tavassoly, S. Nokhrin, O.Y. Dmitriev, J.S. Lee, $\mathrm{Cu}(\mathrm{II})$ and dopamine bind to $\alpha$-synuclein and cause large conformational changes, FEBS J 281(12) (2013) 2738-53.

[37] S.C. Drew, S.L. Leong, C.L. Pham, D.J. Tew, C.L. Masters, L.A. Miles, R. Cappai, K.J. Barnham, Cu ${ }^{2+}$ binding modes of recombinant $\alpha$-synuclein - insights from EPR spectroscopy, J Am Chem Soc 130(24) (2008) 7766-73.

[38] N.B. Cole, D.D. Murphy, J. Lebowitz, L. Di Noto, R.L. Levine, R.L. Nussbaum, Metal-catalyzed oxidation of $\alpha$-Synuclein: helping to define the relationship between oligomers, protofibrils, and filaments, J Biol Chem 280(10) (2005) 9678-90.

[39] S.R. Paik, H.J. Shin, J.H. Lee, Metal-catalyzed oxidation of $\alpha$-Synuclein in the presence of Copper(II) and hydrogen peroxide, Arch Biochem Biophys 378(2) (2000) 269-77.

[40] S.R. Paik, H.J. Shin, J.H. Lee, C.S. Chang, J. Kim, Copper(II)-induced self-oligomerization of $\alpha$-Synuclein, Biochem J 340 ( Pt 3) (1999) 821-8.

[41] V.N. Uversky, J. Li, A.L. Fink, Metal-triggered structural transformations, aggregation, and fibrillation of human $\alpha$-Synuclein. A possible molecular NK between Parkinson's disease and heavy metal exposure, J Biol Chem 276(47) (2001) 44284-96.

[42] G. Zhao, N.D. Chasteen, Oxidation of Good's buffers by hydrogen peroxide, Anal Biochem 349(2) (2006) 262-7.

[43] C. Sahin, N. Lorenzen, L. Lemminger, G. Christiansen, I.M. Møller, L.B. Vesterager, L.O. Pedersen, K. Fog, P. Kallunki, D.E. Otzen, Antibodies against the C-terminus of $\alpha$-synuclein modulate its fibrillation, Biophys Chem 220 (2017) 34-41.

[44] R.F. Beers, Jr., I.W. Sizer, A spectrophotometric method for measuring the breakdown of hydrogen peroxide by catalase, J Biol Chem 195(1) (1952) 133-40.

[45] L. Bousset, L. Pieri, G. Ruiz-Arlandis, J. Gath, P.H. Jensen, B. Habenstein, K. Madiona, V. Olieric, A. Bockmann, B.H. Meier, R. Melki, Structural and functional characterization of two alpha-synuclein strains, Nat Commun 4 (2013) 2575.

[46] B. Rey, C. Degletagne, J. Bodennec, P.A. Monternier, M. Mortz, D. Roussel, C. Romestaing, J.L. Rouanet, J. Tornos, C. Duchamp, Hormetic response triggers multifaceted anti-oxidant strategies in immature king penguins (Aptenodytes patagonicus), Free Radic Biol Med 97 (2016) 577-587.

[47] P.K. Smith, R.I. Krohn, G.T. Hermanson, A.K. Mallia, F.H. Gartner, M.D. Provenzano, E.K. Fujimoto, N.M. Goeke, B.J. Olson, D.C. Klenk, Measurement of protein using bicinchoninic acid, Anal Biochem 150(1) (1985) 76-85.

[48] F. Leinisch, M. Mariotti, M. Rykaer, C. Lopez-Alarcon, P. Hagglund, M.J. Davies, Peroxyl radical- and photo-oxidation of glucose 6-phosphate dehydrogenase generates cross-links and functional changes via oxidation of tyrosine and tryptophan residues, Free Radic Biol Med 112 (2017) 240-252.

[49] A.C. Kramer, P.W. Thulstrup, M.N. Lund, M.J. Davies, Key role of cysteine residues and sulfenic acids in thermal- and $\mathrm{H}_{2} \mathrm{O}_{2}$-mediated modification of $\beta$-lactoglobulin, Free Radic Biol Med 97 (2016) 544-555. 
Running title: Copper-ion catalyzed oxidation of $\alpha$-synuclein

[50] A. Iyer, S.J. Roeters, N. Schilderink, B. Hommersom, R.M. Heeren, S. Woutersen, M.M. Claessens, V. Subramaniam, The impact of N-terminal acetylation of $\alpha$-synuclein on phospholipid membrane binding and fibril structure, J Biol Chem 291(40) (2016) 21110-21122.

[51] A. Iwai, E. Masliah, M. Yoshimoto, N. Ge, L. Flanagan, H.A. de Silva, A. Kittel, T. Saitoh, The precursor protein of non-A $\beta$ component of Alzheimer's disease amyloid is a presynaptic protein of the central nervous system, Neuron 14(2) (1995) 467-75.

[52] A. Hopt, S. Korte, H. Fink, U. Panne, R. Niessner, R. Jahn, H. Kretzschmar, J. Herms, Methods for studying synaptosomal copper release, J Neurosci Methods 128(1-2) (2003) 159-72.

[53] M.L. Schlief, J.D. Gitlin, Copper homeostasis in the CNS: a novel link between the NMDA receptor and copper homeostasis in the hippocampus, Mol Neurobiol 33(2) (2006) 81-90.

[54] E.R. Stadtman, C.N. Oliver, Metal-catalyzed oxidation of proteins. Physiological consequences, J Biol Chem 266(4) (1991) 2005-8.

[55] C. Wang, L. Liu, L. Zhang, Y. Peng, F. Zhou, Redox reactions of the $\alpha$-synuclein- $\mathrm{Cu}^{2+}$ complex and their effects on neuronal cell viability, Biochemistry 49(37) 8134-8142.

[56] J. Yin, J.W. Chu, M.S. Ricci, D.N. Brems, D.I. Wang, B.L. Trout, Effects of antioxidants on the hydrogen peroxide-mediated oxidation of methionine residues in granulocyte colony-stimulating factor and human parathyroid hormone fragment 13-34, Pharm Res 21(12) (2004) 2377-83.

[57] W.J. Ma, E.H. Cao, J.F. Qin, The involvement of singlet oxygen in copper-phenanthroline/H2O2-induced DNA base damage: a chemiluminescent study, Redox Rep 4(6) (1999) 271-276.

[58] T. Ookawara, N. Kawamura, Y. Kitagawa, N. Taniguchi, Site-specific and random fragmentation of Cu,Znsuperoxide dismutase by glycation reaction. Implication of reactive oxygen species, J Biol Chem 267(26) (1992) 18505-10.

[59] W.J. Ferguson, K.I. Braunschweiger, W.R. Braunschweiger, J.R. Smith, J.J. McCormick, C.C. Wasmann, N.P. Jarvis, D.H. Bell, N.E. Good, Hydrogen ion buffers for biological research, Anal Biochem 104(2) (1980) 300-10.

[60] S. Stepanova, V. Kasicka, Recent applications of capillary electromigration methods to separation and analysis of proteins, Anal Chim Acta 933 (2016) 23-42.

[61] J. Stocks, N.E. Miller, Capillary electrophoresis to monitor the oxidative modification of low density lipoproteins, J Lipid Res 39(6) (1998) 1305-9.

[62] D. Weber, M.J. Davies, T. Grune, Determination of protein carbonyls in plasma, cell extracts, tissue homogenates, isolated proteins: Focus on sample preparation and derivatization conditions, Redox Biol 5 (2015) 367-80.

[63] S.B. Nimse, D. Pal, Free radicals, natural antioxidants, and their reaction mechanisms, RSC Adv 5(35) (2015) 27986-28006.

[64] B.M. Hoey, J. Butler, The repair of oxidized amino acids by antioxidants, Biochim Biophys Acta 791(2) (1984) 212-8.

[65] J.C. Mayo, D.X. Tan, R.M. Sainz, M. Natarajan, S. Lopez-Burillo, R.J. Reiter, Protection against oxidative protein damage induced by metal-catalyzed reaction or alkylperoxyl radicals: comparative effects of melatonin and other antioxidants, Biochim Biophys Acta 1620(1) (2003) 139-150.

[66] Q. Yuan, X. Zhu, L.M. Sayre, Chemical nature of stochastic generation of protein-based carbonyls: metalcatalyzed oxidation versus modification by products of lipid oxidation, Chem Res Toxicol 20(1) (2007) 129-39. 
Running title: Copper-ion catalyzed oxidation of $\alpha$-synuclein

[67] V.M. Monnier, I. Nemet, D.R. Sell, M.F. Weiss, Transition metals and other forms of oxidative protein damage in renal disease, in: T. Miyata, K.-U. Eckardt, M. Nangaku (Eds.), Studies on Renal Disorders, Humana Press, Totowa, NJ, 2011, pp. 25-50.

[68] I.M. Møller, A. Rogowska-Wrzesinska, R.S. Rao, Protein carbonylation and metal-catalyzed protein oxidation in a cellular perspective, J Proteomics 74(11) (2011) 2228-42.

[69] R.J. Mason, A.R. Paskins, C.F. Dalton, D.P. Smith, Copper binding and subsequent aggregation of $\alpha-$ synuclein are modulated by N-terminal acetylation and ablated by the H50Q missense mutation, Biochemistry 55(34) (2016) 4737-41.

[70] A. Binolfi, A. Limatola, S. Verzini, J. Kosten, F.X. Theillet, H.M. Rose, B. Bekei, M. Stuiver, M. van Rossum, P. Selenko, Intracellular repair of oxidation-damaged $\alpha$-synuclein fails to target C-terminal modification sites, Nat Commun 7 (2016) 10251.

[71] C.G. Dudzik, E.D. Walter, G.L. Millhauser, Coordination features and affinity of the $\mathrm{Cu}^{2+}$ site in the $\alpha-$ synuclein protein of Parkinson's disease, Biochemistry 50(11) (2011) 1771-7.

[72] M.J. Davies, The oxidative environment and protein damage, Biochim Biophys Acta 1703(2) (2005) 93109.

[73] S.H. Gellman, On the role of methionine residues in the sequence-independent recognition of nonpolar protein surfaces, Biochemistry 30(27) (1991) 6633-6.

[74] W. Zhou, C. Long, S.H. Reaney, D.A. Di Monte, A.L. Fink, V.N. Uversky, Methionine oxidation stabilizes non-toxic oligomers of $\alpha$-synuclein through strengthening the auto-inhibitory intra-molecular long-range interactions, Biochim Biophys Acta 1802(3) (2010) 322-30.

[75] G.R. Buettner, B.A. Jurkiewicz, Catalytic metals, ascorbate and free radicals: combinations to avoid, Radiat Res 145(5) (1996) 532-41.

[76] C. Cheignon, F. Collin, P. Faller, C. Hureau, Is ascorbate Dr Jekyll or Mr Hyde in the $\mathrm{Cu}(\mathrm{A} \beta)$ mediated oxidative stress linked to Alzheimer's disease?, Dalton Trans 45(32) (2016) 12627-12631.

[77] T. Hoshi, S. Heinemann, Regulation of cell function by methionine oxidation and reduction, J Physiol 531(Pt 1) (2001) 1-11.

[78] V. Kadlcik, C. Sicard-Roselli, T.A. Mattioli, M. Kodicek, C. Houée-Levin, One-electron oxidation of $\beta$ amyloid peptide: sequence modulation of reactivity, Free Radic Biol Med 37(6) (2004) 881-891.

[79] C. Schoneich, D. Pogocki, G.L. Hug, K. Bobrowski, Free radical reactions of methionine in peptides: mechanisms relevant to $\beta$-amyloid oxidation and Alzheimer's disease, J Am Chem Soc 125(45) (2003) 1370013.

[80] A. Binolfi, L. Quintanar, C.W. Bertoncini, C. Griesinger, C.O. Fernández, Bioinorganic chemistry of copper coordination to alpha-synuclein: Relevance to Parkinson's disease, Coord Chem Rev 256(19) (2012) 2188-2201.

[81] Y.C. Chi, G.S. Armstrong, D.N. Jones, E.Z. Eisenmesser, C.W. Liu, Residue histidine 50 plays a key role in protecting alpha-synuclein from aggregation at physiological pH, J Biol Chem 289(22) (2014) 15474-81.

[82] B.E. Sturgeon, H.J. Sipe, Jr., D.P. Barr, J.T. Corbett, J.G. Martinez, R.P. Mason, The fate of the oxidizing tyrosyl radical in the presence of glutathione and ascorbate. Implications for the radical sink hypothesis, $\mathrm{J}$ Biol Chem 273(46) (1998) 30116-21.

[83] L.K. Folkes, M. Trujillo, S. Bartesaghi, R. Radi, P. Wardman, Kinetics of reduction of tyrosine phenoxyl radicals by glutathione, Arch Biochem Biophys 506(2) (2011) 242-9. 
Running title: Copper-ion catalyzed oxidation of $\alpha$-synuclein

[84] N. Bengoa-Vergniory, R.F. Roberts, R. Wade-Martins, J. Alegre-Abarrategui, Alpha-synuclein oligomers: a new hope, Acta Neuropathol 134(6) (2017) 819-838.

[85] M. Ingelsson, Alpha-Synuclein oligomers-neurotoxic molecules in Parkinson's disease and other Lewy body disorders, Front Neurosci 10 (2016) 408.

[86] A.L. Fink, The aggregation and fibrillation of $\alpha$-synuclein, Acc Chem Res 39(9) (2006) 628-34.

[87] B. Alvarez-Castelao, M. Goethals, J. Vandekerckhove, J.G. Castano, Mechanism of cleavage of alphasynuclein by the $20 \mathrm{~S}$ proteasome and modulation of its degradation by the RedOx state of the N-terminal methionines, Biochim Biophys Acta 1843(2) (2014) 352-65.

[88] A.S. Maltsev, J. Chen, R.L. Levine, A. Bax, Site-specific interaction between $\alpha$-Synuclein and membranes probed by NMR-observed methionine oxidation rates, , J Am Chem Soc 135(8) (2013) 2943-2946.

[89] S.L. Leong, C.L. Pham, D. Galatis, M.T. Fodero-Tavoletti, K. Perez, A.F. Hill, C.L. Masters, F.E. Ali, K.J. Barnham, R. Cappai, Formation of dopamine-mediated alpha-synuclein-soluble oligomers requires methionine oxidation, Free Radic Biol Med 46(10) (2009) 1328-37.

[90] L. Chen, M. Periquet, X. Wang, A. Negro, P.J. McLean, B.T. Hyman, M.B. Feany, Tyrosine and serine phosphorylation of $\alpha$-synuclein have opposing effects on neurotoxicity and soluble oligomer formation, J Clin Invest 119(11) (2009) 3257-3265.

[91] B. Winner, R. Jappelli, S.K. Maji, P.A. Desplats, L. Boyer, S. Aigner, C. Hetzer, T. Loher, M. Vilar, S. Campioni, C. Tzitzilonis, A. Soragni, S. Jessberger, H. Mira, A. Consiglio, E. Pham, E. Masliah, F.H. Gage, R. Riek, In vivo demonstration that $\alpha$-synuclein oligomers are toxic, Proc Natl Acad Sci USA 108(10) (2011) 41944199.

[92] S. Krishnan, E.Y. Chi, S.J. Wood, B.S. Kendrick, C. Li, W. Garzon-Rodriguez, J. Wypych, T.W. Randolph, L.O. Narhi, A.L. Biere, M. Citron, J.F. Carpenter, Oxidative dimer formation is the critical rate-limiting step for Parkinson's disease $\alpha$-Synuclein fibrillogenesis, Biochemistry 42(3) (2003) 829-837.

[93] J. Du, J.J. Cullen, G.R. Buettner, Ascorbic acid: chemistry, biology and the treatment of cancer, Biochim Biophys Acta 1826(2) (2012) 443-57.

[94] A.S. Domazou, W.H. Koppenol, J.M. Gebicki, Efficient repair of protein radicals by ascorbate, Free Radic Biol Med 46(8) (2009) 1049-57.

[95] W. Vogt, Oxidation of methionyl residues in proteins: tools, targets, and reversal, Free Radic Biol Med 18(1) (1995) 93-105.

[96] T. Nauser, J. Pelling, C. Schöneich, Thiyl radical reaction with amino acid side chains: rate constants for hydrogen transfer and relevance for posttranslational protein modification, Chem Res Toxicol 17(10) (2004) 1323-1328.

[97] A. Binolfi, E.E. Rodriguez, D. Valensin, N. D’Amelio, E. Ippoliti, G. Obal, R. Duran, A. Magistrato, O. Pritsch, M. Zweckstetter, G. Valensin, P. Carloni, L. Quintanar, C. Griesinger, C.O. Fernández, Bioinorganic chemistry of Parkinson's disease: structural determinants for the copper-mediated amyloid formation of alphasynuclein, Inorganic Chemistry 49(22) (2010) 10668-10679.

[98] W.A. Prutz, J. Butler, E.J. Land, Phenol coupling initiated by one-electron oxidation of tyrosine units in peptides and histone, Int J Radiat Biol Relat Stud Phys Chem Med 44(2) (1983) 183-96.

[99] Y. Kato, N. Kitamoto, Y. Kawai, T. Osawa, The hydrogen peroxide/copper ion system, but not other metalcatalyzed oxidation systems, produces protein-bound dityrosine, Free Radic Biol Med 31(5) (2001) 624-632. 
Running title: Copper-ion catalyzed oxidation of $\alpha$-synuclein

[100] J.M. Gebicki, T. Nauser, A. Domazou, D. Steinmann, P.L. Bounds, W.H. Koppenol, Reduction of protein radicals by GSH and ascorbate: potential biological significance, Amino Acids 39(5) (2010) 1131-7. 